Vivian C. Trevine

\title{
Sistemática da tribo Tachymenini Bailey, 1967 (Serpentes, Dipsadidae, Xenodontinae)
}

Systematics of the tribe Tachymenini Bailey, 1967 (Serpentes, Dipsadidae, Xenodontinae) 


\section{INTRODUÇÃO}

\subsection{Sistemática de serpentes Caenophidia e a subfamília Xenodontinae}

Dentro da Herpetologia, a morfologia sempre serviu como um alicerce para fundamentar as classificações dos grupos de Squamata (Cope, 1892; Dunn, 1928; Romer, 1956; Underwood, 1967; Marx \& Rabb, 1972; Dowling \& Duellmanm, 1978; Jenner \& Dowling, 1985; McDowell, 1987; Estes et al., 1988; Cundall \& Irish, 2008; Gauthier et al., 2012). A partir das décadas de 80 e 90, o uso de dados moleculares ganhou espaço, passando a representar a fonte de dados mais utilizada na sistemática de Serpentes (e.g. Dowling et al., 1983; 1996; Heise et al.,1995; Kraus \& Brown, 1998; Vidal et al., 2000; Lenk et al., 2001; Slowinski \& Lawson, 2002; Vidal \& Hedges, 2002; Wilcox et al., 2003; Pinou et al., 2004; Burbrink, 2005; Oguiura et al., 2010; Mulcahy et al., 2011; Pyron et al., 2014). Nesse sentido, há um consenso sobre a necessidade de combinação de métodos moleculares e morfológicos em busca de um conhecimento abrangente e integrativo da evolução de Squamata (Wiens, 2004; 2009; Reeder et al., 2015).

Dentro de Caenophidia, o agrupamento tradicionalmente denominado como "Colubridae" englobava a maior diversidade de serpentes (Underwood, 1967; Dowling \& Duellman, 1978; McDowell, 1987; Cadle, 1994; Ferrarezzi, 1994; Zaher, 1999). Contudo, por ser um grupo frequentemente recuperado como parafilético (Kelly et al., 2003; Lawson et al., 2005; Vidal et al., 2007; Zaher et al., 2009a), diversas alterações no conteúdo e abrangência de Colubridae foram propostas, buscando refletir a diversidade evolutiva e os clados recém descobertos (Zaher et al., 2009a; Pyron et al., 2011). Os níveis categóricos de Caenophidia foram rebaixados para posições menos inclusivas, sendo o nome Colubroides empregado no lugar de Colubroidea; e a superfamília Colubroidea, por sua vez, aplicada para o agrupamento das seis famílias retiradas da classificação tradicional de "Colubridae" (Calamaridae, Colubridae, Dipsadidae, Natricidae, Pseudoxenodontidae e Sibynophiidae) (Zaher et al., 2009a; Grazziotin et al., 2012; Zaher et al., 2012).

Dentre as famílias de Colubroidea, Dipsadidae abriga a maior diversidade, e é representada por três linhagens neotropicais historicamente distintas (Cadle 1984a, 1984b; Vidal et al., 2000; Pinou et al., 2004). Assim, existe um consenso atual na divisão dos Xenodontinae (lato sensu): xenodontíneos sulamericanos (Xenodontinae stricto sensu), centro-americanos (Dipsadíneos), e xenodontíneos norte-americanosque incluem os gêneros incertae sedis (Heterodon, Farancia e Thermophis) (Cadle 1984c; Ferrarezzi, 1994; Zaher, 1999; Pinou et al., 2004; Lawson et al., 2005; Vidal et al., 2007; Zaher et al., 2009a; Grazziotin et al., 2012). 
Alguns agrupamentos tribais de Xenodontinae (stricto sensu ) vêm sendo recorrentemente corroborados por sinapomorfias morfológicas e por evidências moleculares, como Elapomorphini, Hydropsini, Pseudoboini, Xenodontini e Tachymenini (Dixon, 1980; Ferrarezzi, 1994; Zaher, 1999; Moura-Leite, 2001; Nunes, 2006; Zaher et al., 2009a; Vidal et al., 2010; Grazziotin et al., 2012). Contudo, diversos grupos encontram-se ainda sem resolução, decorrentes de problemas taxonômicos históricos, plasticidade fenotípica, ou ainda, déficits amostrais (Zaher, 1999; Grazziotin et al., 2012; Myers \& McDowell, 2014).

\subsection{Diversidade e Sistemática da tribo Tachymenini}

Bailey (1967) definiu a tribo Tachymenini para alocar os "vários outros gêneros relacionados à Thamnodynastes, designando o hábito "ovíparo" como caráter unificante mais significativo para o grupo (posteriormente corrigido para vivíparo em Bailey, 1981). Tais gêneros, Tachymenis, Thamnodynastes, Tomodon, Ptychophis, Gomesophis, Pseudotomodon e, provavelmente, Calamodontophis (de acordo com publicação original), foram elencados no ano anterior como um grupo supra genérico proximamente relacionado de serpentes da América do Sul (Bailey, 1966a).

Esse grupo foi diagnosticado por abrigar serpentes de pequeno a médio porte; vivíparas; opistóglifas; com pupila vertical; e padrão de coloração da cabeça formado por uma barra escura do olho à curvatura da boca (exceto em Calamodontophis) (Bailey, 1966a; 1967; 1981). Além disso, diversos outros caracteres morfológicos diagnósticos (não sinapomórficos) foram descritos e corroborados para a tribo: osso pós-orbital separado do frontal pelo parietal; placa nasal semi-dividida; pupila vertical ou semi-elíptica; dimorfismo sexual invertido na contagem de escamas ventrais (i.e. machos com maior número de ventrais); glândula de Duvernoy aderida ao músculo adductor mandibulae externus superficialis, além de alguns caracteres hemipenianos (Bailey, 1966a, 1967; Ferrarezzi, 1994; Zaher, 1999; Franco, 2000; Zaher et al., 2009a).

Atualmente são reconhecidas 33 espécies válidas para a tribo: duas de Calamodontophis, seis de Tachymenis, 19 de Thamnodynastes, três de Tomodon, e três nos gêneros monotípicos Gomesophis, Ptychophis e Pseudotomodon (Tabela 1) (Franco \& Ferreira, 2002; Bailey \& Thomas, 2005; Bailey et al., 2007); além de mais duas outras espécies sem nome, de acordo com Franco \& Ferreira (2002): Thamnodynastes sp. 1 e Thamnodynastes sp. 2. A diversidade ecológica dentre as espécies é expressiva, ocupando zonas florestadas, abertas, pantanosas ou secas; distribuídas por toda a América do Sul, do nível do mar até altitudes superiores à 4.000 metros. Seus hábitos são igualmente diversos, com espécies semi-arborícolas, terrestres, semi- 
aquáticas ou aquáticas. Alimentam-se de invertebrados, como anelídeos e lesmas, ou vertebrados, como peixes, anfíbios e lagartos (Gallardo, 1972; Bernarde et al., 2000a; 2000b; Oliveira et al., 2003; Bizerra et al., 2005; Bellini et al., 2014).

Apesar da validade de Tachymenini ter sido contestada por alguns autores (Dowling \& Duellman, 1978; Jenner, 1981; Zaher, 1999), seu monofiletismo vem sendo corroborado com elevado suporte, tanto por trabalhos morfológicos (Ferrarezzi, 1994; Franco, 2000), quanto moleculares (Vidal et al., 2000; Zaher et al., 2009a; Vidal et al., 2010; Grazziotin et al., 2012). Entretanto, a instabilidade taxonômica e filogenética dentro da tribo é historicamente reconhecida (Phillipi, 1899; Peters \& Orejas-Miranda, 1970; Vanzolini et al., 1980; Cei et al., 1992; Franco, 2000; Bailey et al., 2005; Bailey \& Thomas, 2007). Há décadas diversos autores vêm alertando sobre a necessidade de revisão dos gêneros Tachymenis, Thamnodynastes e Tomodon, denotando a dificuldade na identificação das espécies com base nas diagnoses disponíveis (Roze, 1966; Myers \& Hoogmoed, 1974; Hoogmoed, 1982; Vanzolini, 1986; Pérez-Santos \& Moreno, 1989; Franco, 2000; Bailey et al., 2007).

Um dos primeiros autores a considerar o relacionamento dos gêneros de Tachymenini foi Fitzinger (1843), que considerou Thamnodynastes e Dryophylax no grupo do gênero Dipsadomorphus, família Cephalophes, e Tachymenis no grupo do gênero Ophis, família Dermatophes. Günther (1858) dividiu os taquimeníneos em três famílias, Coronellidae (Tachymenis chilensis), Natricidae (Tomodon strigatus e Tomodon dorsatus) e Dipsadidae (Thamnodynastes nattereri e Thamnodynastes punctatissimus). Cope (1895) considerou os gêneros Thamnodynastes, Tomodon e Tachymenis na família Dipsadidae, subfamília Scytalinae. Boulenger (1896) distinguiu Tachymenis de Thamnodynastes pela presença de dentes mandibulares anteriores mais longos no primeiro, e dentes "subiguais" no segundo.

Dunn (1928) incluiu Tachymenis, Thamnodynastes, Tomodon e Pseudotomodon em Ophiinae, e considerou o último provavelmente relacionado com o anterior. Amaral (1929) considerou Tachymenis brasiliensis, Dryophylax (=Thamnodynastes) pallidus, Tomodon dorsatus, Tomodon ocellatus e Ptychophis flavovirgatus dentro da subfamília Boiginae, família Colubridae. Bailey (1966a, 1967, 1981) então definiu Tachymenini, agrupando os sete gêneros atualmente reconhecidos (ver Tabela 1).

Após o trabalho de Bailey (1967), alguns autores discordaram da composição da tribo, fornecendo classificações próprias e baseados em poucas características morfológicas. Dowling \& Duellman (1978) consideraram Calamodontophis, Gomesophis, Ptychophis, Tachymenis e Thamnodynastes como pertencentes à tribo Alsophiini; e Pseudotomodon e Tomodon à tribo Hydropsini. Jenner (1981) incluiu Pseudotomodon, Gomesophis e 
Ptychophis em Diaphorolepini, e os outro quatro gêneros em Philodryadini. Blackburn (1985) classificou Ptychophis, Tachymenis e Thamnodynastes como representantes vivíparos da subfamília Alsophiinae, presumindo que a viviparidade nesses três gêneros tivesse uma origem comum. Já Ferrarezzi (1994) reconheceu Tachymenini sensu Bailey, com base em características de morfologia externa (placa nasal semi-dividida, placa anal dividida e pupila vertical), osteologia craniana (dentição opistóglifa com diastema, osso pos-órbital separado do frontal pelo parietal) e padrão hemipeniano, considerando a viviparidade como a única sinapomorfia da tribo.

Em sua tese tratando das relações filogenéticas de Tachymenini, Franco (2000) apresentou uma análise de Máxima Parcimônia de uma matriz de 71 caracteres morfológicos com 54 táxons. $\mathrm{O}$ autor utilizou pesagem sucessiva para melhorar a resolução das árvores igualmente parcimoniosas, porém seu cladograma final ainda apresentou diversas politomias. $\mathrm{O}$ posicionamento da tribo em Xenodontinae apareceu como incerto, com o gênero Manolepis como grupo-irmão, ou com os taquimeníneos agrupados com membros das tribos Philodryadini, Alsophiini e Pseudoboini (Franco, 2000). Entretanto a tribo foi recuperada como monofilética e dividida em duas linhagens: uma incluindo Thamnodynastes spp. e outra os demais táxons. A partir da topologia encontrada, Franco (2000) designou todos os táxons da linhagem irmã de Thamnodynastes, exceto Gomesophis e Ptychophis, como pertencentes ao gênero Tachymenis, e sinonimizou Gomesophis com Ptychophis; restringindo, portanto, os taquimeníneos a três gêneros: Ptychophis, Tachymenis e Thamnodynastes.

O primeiro trabalho a utilizar todos os gêneros da tribo em uma análise filogenética molecular foi o de Zaher et al. (2009a), o qual apresentou uma filogenia de Caenophidia baseada em três genes e 131 terminais. Neste trabalho, Tachymenini foi posicionada como grupo-irmão de Tropidodryadini, apesar de ser um dos agrupamentos com menor valor de suporte. Dois grupos-irmãos foram obtidos dentro da tribo: um composto por Pseudotomodon trigonatus e Tachymenis peruviana, por sua vez inserido no grupo formado por Ptychophis flavovirgatus, Calamondotophis paucidens e Gomesophis brasiliensis; e o segundo formado por Tomodon dorsatus e Thamnodynastes spp. (Zaher et al., 2009a). Já Vidal et al. (2010) e Pyron et al. (2011) apresentaram uma árvore filogenética molecular na qual os taquimeníneos aparecem como grupo irmão de Hydropsini, apesar do segundo estudo ter apresentado somente To. dorsatus como terminal. Adicionalmente, na filogenia de Vidal et al. (2010), Gomesophis aparece como grupo irmão dos demais taquimeníneos; P. trigonatus insere-se dentro de Tachymenis e To. dorsatus agrupa-se com Thamnodynastes pallidus, denotando o gênero Thamnodynastes como polifilético, apesar do baixo suporte. 
Posteriormente, Grazziotin et al. (2012) recuperaram novamente a relação entre Tachymenini e Tropidodryadini, em uma análise que passou a incluir um maior número de genes. Apesar de Tachymenis e Thamnodynastes terem sido recuperados novamente como não-monofiléticos, o suporte para os clados dentro da tribo foi muito baixo, exceto para o agrupamento de $P$. trigonatus com Ta. peruviana, e para o clado com as Thamnodynastes excluindo Th. pallidus (Grazziotin et al., 2012). O trabalho de Pyron et al. (2013) recuperou Tachymenini como grupo irmão de Hydropsini + Manolepis putnami com bom suporte. Nessa topologia Thamnodynastes foi recuperado como monofilético; $P$. trigonatus agrupou-se novamente com Tachymenis, e Gomesophis apareceu como táxon irmão de todos os outros taquimeníneos.

Em um trabalho mais recente, com uma amostragem mais ampla com 1745 táxons e 10 genes, Figueroa et al. (2016) recuperaram Tachymenini agrupada com Pseudoboini, com bom suporte. Os autores apresentaram relações similares às propostas em trabalhos anteriores: Gomesophis como irmão de todos os taquimeníneos e $P$. trigonatus agrupada com Tachymenis, porém com Thamnodynastes monofilético, apesar da espécie tipo do gênero, Th. pallidus, não ter sido incluída na análise.

Fora a tese não publicada de Franco (2000), nenhum autor considerou exclusivamente as relações filogenéticas dos taquimeníneos, especialmente o posicionamento dos gêneros e agrupamentos das espécies. Ao mesmo tempo, nenhuma filogenia proposta até o momento apresentou, concomitantemente, boa amostragem taxonômica e suporte para as relações filogenéticas de Tachymenini.

Nesse sentido, o presente trabalho combinou dados morfológicos e moleculares do maior número de espécies dos sete gêneros atualmente reconhecidos dentro de Tachymenini, procurando aprimorar o conhecimento das relações evolutivas entre seus membros, assim como seu posicionamento filogenético dentro de Xenodontinae.

\subsection{Histórico taxonômico dos gêneros de Tachymenini}

\section{O gênero Thamnodynastes}

Thamnodynastes é o gênero mais especioso dentre os taquimeníneos, e como tal, apresenta um extenso e complicado histórico taxonômico (Wagler, 1830; Amaral, 1926; Prado, 1942; Hoge, 1952; Bailey et al., 2007). A descrição precária de várias espécies, resultando na ausência de características diagnósticas robustas e diferenciáveis entre elas, é o principal fator para os recorrentes erros de identificação e a dificuldade em quantificar a diversidade do gênero (Roze, 1958; Vanzolini, 1986; Pérez-Santos \& Moreno, 1989; Görzula \& 
Ayarzagüena, 1995; Myers \& Donnelly, 1996; Bailey et al., 2005; Manzanilla \& Sanchez, 2005).

A espécie tipo, Coluber pallidus, foi descrita por Linnaeus, 1758. Em seguida Coluber strigilis foi descrita por Thunberg, 1787; e a terceira, Coluber nattereri, foi descrita por Mikan, 1820. Wagler (1824) descreveu Natrix punctatissima baseado em um exemplar da Bahia, com 158 ventrais e 85 subcaudais. Posteriormente, Wagler (1830) descreveu o gênero Dryophylax para abrigar Coluber nattereri Mikan, 1820 como espécie tipo (Wagler, 1830, p.181); e, no mesmo trabalho, criou o gênero Thamnodynastes para incorporar Natrix punctatissima Wagler, 1824 (Wagler, 1830, p.182). Schlegel (1837) elencou Dipsas nattereri e Dipsas punctatissima, a primeira com 17 escamas lanceoladas do Brasil; e a segunda, similar à primeira, com escamas lisas e cauda mais fina, da região Amazônica. Fitzinger (1843) reiterou as espécies de Wagler $(1824,1830)$, Thamnodynastes punctatissimus e Dryophylax nattereri.

Günther (1858) considerou somente Thamnodynastes nattereri e Th. punctatissimus, e, assim, alocou o gênero Dryophylax Wagler, 1830 como sinônimo júnior de Thamnodynastes. Logo, o nome Thamnodynastes foi mantido para o gênero (Amaral, 1926; Parker, 1935; Amaral, 1944).

Em seu catálogo, Günther (1858) descreveu também Tomodon strigatus para "India" e o alocou com Tomodon dorsatus na família Natricidae. O autor diagnosticou To. strigatus por uma faixa preta fina de cada lado do corpo da narina à cauda, e uma faixa de cada lado do ventre até a ponta da cauda (Günther, 1858). O autor considerou como Th. nattereri os táxons da região Amazônica (Demerara, Guiana) e do estado do Rio de Janeiro, diferenciando-a de Th. punctatissimus pela presença de quilhas e pela cauda equivalente a menos de um quarto do comprimento total. No mesmo trabalho Günther (1858) examinou dois espécimes de $T h$. punctatissimus, um com a escama cloacal inteira e o outro dividida, e caracterizou a espécie por possuir quatro linhas longitudinais ventrais formadas por pontos pequenos que se confluem na cauda, escamas lisas e cauda equivalente à quase um terço do comprimento total (Günther, 1858).

Jan (1863) descreveu Mesotes obtrusus para Buenos Aires, Argentina, e sua variedade Mesotes obtrusus var. plataensis de La Plata, Argentina (Jan, 1863; Jan \& Sordelli, 1866). Boulenger (1885) descreveu Thamnodynastes nattereri var. laevis para o Rio Grande do Sul, e alocou Th. punctatissimus na sinonímia de Th. nattereri. Segundo o autor, essa variedade (laevis) apresenta 142 ou 143 ventrais e 62 ou 63 subcaudais; e corresponderia, ao mesmo tempo, à Th. nattereri, pela cauda menor que um quarto do comprimento total, e à $T h$. 
punctatissimus, pelas escamas lisas. No ano seguinte, o mesmo autor considerou duas espécies, Th. nattereri (escamas quilhadas) e Th. strigatus (escamas lisas), alocando dentro da última Mesostes obtrusus Jan, 1863, e o seu táxon Th. nattereri var. laevis (Boulenger, 1886). No terceiro volume do seu catálogo, Boulenger considerou Th. nattereri e Th. punctatissimus como espécies distintas (Boulenger, 1896). Desta vez, o autor sinonimizou Mesotes obtrusus Jan, 1863, Th. punctatissimus Hensel, 1868, Th. strigatus Boulenger, 1886, Th. nattereri var. laevis Boulenger, 1885, e Tachymenis hypoconia Cope, 1860 à Th. nattereri; e N. punctatissima Wagler, 1824 e Th. punctatissimus Gunther, 1858 à Th. punctatissimus (Boulenger, 1896). Dentro de "Th. nattereri", o autor elencou as formas de escamas fortemente quilhadas do Pará, Rio de Janeiro e Uruguai; moderadamente quilhadas do Rio de Janeiro e Paraguai; fracamente quilhadas da Guiana e Rio de Janeiro; e de escamas lisas de Aracati, no Ceará e Rio Grande do Sul, incluindo aqui o tipo de Tomodon strigatus como uma Th. nattereri de escamas lisas (Boulenger, 1896).

Cope (1887) alocou Tachymenis hypoconia Cope, 1860 e Tomodon strigatus Günther, 1858 na sinonímia de Tachymenis strigatus. Em outro ano, o mesmo autor elencou as espécies Th. nattereri e Th. strigatus para o gênero (Cope, 1895).

Lönnberg (1896) refutou Coluber strigilis Thunberg, 1787 identificando-a como Th. nattereri (Günther, 1858). Pela lei da prioridade o autor manteve o nome de Thunberg, definindo então Thamnodynastes strigilis (Coluber strigilis + Coluber [Dryophylax, Thamnodynastes] nattereri) (Lönnberg, 1896).

Andersson (1899), ao publicar o catálogo de tipos de Linnaeus, identificou um exemplar (com 17 dorsais, 157 ventrais e 94 subcaudais) que corresponde à descrição original de Coluber pallidus Linnaeus, 1758; e confirmou a sua identidade como Th. punctatissimus de Wagler (1830). Consequentemente o autor alocou Th. punctatissimus na sinonímia de Thamnodynastes pallidus (Andersson, 1899).

Amaral (1926) considerou Thamnodynastes como monotípico, posicionando Th. punctatissimus, Th. strigilis e Th. nattereri como sinônimos de Th. pallidus. O autor aceitou as mudanças de Andersson (1899) e de Lonnberg (1896), e considerou as características utilizadas por Boulenger (1896) para separar Th. strigilis (=Coluber strigilis) de Th.pallidus (=Th . punctatissimus) somente como variações individuais ("corpo menos delgado; olho menor; rostral mais larga do que alta; escamas lisas, ou mais ou menos fortemente carinadas em 19 fileiras; anal dividida; subcaudais 48-78"). Logo, Amaral (1926) considerou todas as outras espécies de Thamnodynastes como variações de Th. pallidus. Em seguida, Amaral (1929) designou o gênero Dryophylax para Coluber pallidus Linnaeus, 1758. O autor 
considerou a "forma strigilis = nattereri" (Amaral, 1929, p.34), e reconheceu duas subespécies: Dryophylax pallidus pallidus (Coluber pallidus; sinônimo = Th . punctatissimus) e Dryophylax pallidus strigilis (Coluber strigilis; sinônimo = Th. nattereri); a primeira do nordeste e norte do Brasil, e a segunda do sul, centro e oeste (Amaral, 1929).

Parker (1935) corrigiu a classificação de Amaral (1929), esclarecendo que a prioridade do gênero Thamnodynastes deve ser mantida. Já Brongersma (1940) questionou as subespécies de Amaral (1929) e afirmou que a classificação de Boulenger (1896) é valida. Apesar de mencionar a ausência de material suficiente para confirmar suas decisões taxonômicas, o autor reconheceu Dryophylax strigilis como uma espécie distinta, com base em um exemplar da Colômbia; e alocou em sua sinonímia Th. nattereri e Th. pallidus (Brongersma, 1940).

Prado (1942) descreveu Dryophylax rutilus para o município de Gália, São Paulo, caracterizada por uma mancha vermelha na sétima infralabial. O autor alocou espécie nesse gênero por características cranianas e outros "caracteres genéricos", e mencionou a necessidade de revisão de Dryophylax, ainda considerado fundido com Philodryas pelo autor. Prado (1942) ainda relacionou $D$. rutilus à $D$. strigilis, a última restrita ao centro e sul do país; porém, pelas diferenças encontradas nas duas espécies, o autor propõs que $D$. strigilis se enquadraria melhor no gênero Thamnodynastes. No ano seguinte, Prado (1943) afirmou que D. strigilis e D. pallidus deveriam pertencer ao gênero Thamnodynastes.

Amaral (1944) rejeitou as afirmações genéricas de Prado (1942), afirmando que Dryophylax e Thamnodynastes encontram-se fundidos desde Boulenger (1896). O autor ainda descartou a diagnose apresentada por Prado $(1942 ; 1943)$, por este ter utilizado somente fêmeas em sua descrição; e considerou $D$. rutilus como uma variação de Th. pallidus strigilis (ou Th. strigilis) (Amaral, 1944). Em sequência, Prado (1947) descreveu o hemipênis do alótipo de $D$. rutilus, fornecendo evidências para removê-lo da sinonímia de Th. pallidus strigilis. Vanzolini (1948) aceitou o táxon de Prado (1942) como Thamnodynastes rutilus, porém questionou o seu posicionamento genérico pela dificuldade em encontrar características diagnósticas no único exemplar examinado, proveniente de Cachoeira de Emas, Pirassununga, SP.

Hoge (1952) redescreveu Thamnodynastes strigatus, esclarecendo a confusão deixada por Boulenger (1886; 1896). Neste trabalho, Hoge (1952) menciona que, na descrição original dessa espécie, Günther (1858) não forneceu o número de ventrais do tipo; porém no catálogo de Boulenger foram apresentadas as seguintes informações para o tipo de Tomodon strigatus: fêmea com 133 ventrais e 56 subcaudais (Boulenger, 1896, p.117). Com base nos dados de Boulenger (1896), Hoge (1952) concluiu que o estado de São Paulo poderia ser indicado 
como pátria provável e, dessa maneira, designou um alótipo para Th. strigatus (IBSP 1482, macho) procedente de Pindamonhangaba, SP, no qual baseou sua redescrição.

Dentre as espécies citadas anteriormente, os maiores problemas taxonômicos estão associados à Th. pallidus e Th. strigilis. Lönnberg (1896) mencionou brevemente que o tipo de Coluber pallidus Linnaeus, 1758 encontrava-se perdido. Andersson (1899) relatou que o tipo de Linnaeus encontra-se na coleção do Museu Real de Stockholm, e redefiniu o táxon Th. pallidus. No início do século seguinte, alguns autores propuseram outras classificações para Th. pallidus, que foram sequencialmente refutadas (e.g. Amaral, 1926; 1929; Parker, 1935; Brongersma, 1940) (ver parágrafos acima). Peters \& Orejas-Miranda (1970) consideraram Natrix punctatissima como sinônimo de Th. pallidus, e alocaram Coluber nattereri na sinonímia de Th. strigilis. A diagnose de Th. pallidus, segundo Peters \& Orejas-Miranda (1970), seria a presença de 17 fileiras de escamas dorsais, 144-159 ventrais e 90-97 subcaudais, com distribuição no Brasil, Guiana, Peru e Venezuela.

Já o táxon Th. strigilis representava um "nome coringa" para as espécies que não se encaixavam nas descrições disponíveis de Thamnodynates, portanto sem uma diagnose clara, e abrangendo formas da Argentina, Brasil, Colômbia, Guiana, Paraguai, Suriname, Uruguai e Venezuela (Peters \& Orejas-Miranda, 1970; Abuys, 1986). Para Peters \& Orejas-Miranda (1970) são sinônimos de Th. strigilis: Coluber strigilis, C. nattereri, Tachymenis hypoconia e Th. nattereri var. laevis.

A partir do final da década de 80, descrições de espécies do "complexo strigilis" foram sendo publicadas, iniciando o esclarecimento de algumas questões taxonômicas. Bailey et al. (2005) alocaram Th. strigilis (Thunberg, 1787) na sinonímia de Th.pallidus (Linnaeus, 1758), designando um neótipo para a última. Os mesmos autores designaram o "grupo pallidus" para abranger as espécies com corpo mais afinado, maior tamanho do corpo, maior número de subcaudais, cabeça curta, olhos maiores, menor contagem de escamas dorsais, escamas dorsais lisas e comportamento de achatamento dorso lateral do pescoço (hood-display) (Bailey et al., 2005). O trabalho de Cei et al. (1992) revalidou Thamnodynastes hypoconia, redescrevendo a espécie com base em uma foto do tipo de Tachymenis hypoconia Cope, 1860. No ano seguinte, Thamnodynastes chaquensis foi descrita para o nordeste argentino, distinta de Th. hypoconia por suas maiores dimensões, corpo robusto, quilha percorrendo dois terços da escama dorsal sem chegar ao ápice, e pelo hemipênis (Bergna \& Alvarez, 1993). Dessa forma, as formas conhecidas como Th. strigilis na Argentina foram separadas em duas espécies distintas, Th. hypoconia (revalidada) e Th. chaquensis (Cei et al., 1992; Bergna \& Alvarez, 1993; Giraudo \& Scrocchi, 2002). 
Outros pesquisadores focaram-se nas formas de Th. strigilis e Th. pallidus da Colômbia e Venezuela, resultando na descrição de nove outras espécies: Thamnodynastes gambotensis da região caribenha do norte da Colômbia (Pérez-Santos \& Moreno, 1989); Thamnodynastes corocoroensis e Thamnodynastes marahuaquensis dos tepuis venezuelanos (Gorzula \& Ayarzagüena, 1995); Thamnodynastes duida e Thamnodynastes yavi, dos cerros (tepuis) Duida e Yavi, respectivamente, do estado Amazonas, Venezuela (Myers \& Donnelly, 1996); Thamnodynastes ramonriveroi do Maciço de Turimirique, noroeste da Venezuela (Manzanilla \& Sánchez, 2005); Thamnodynastes ceibae e Thamnodynastes paraguanae, da bacia do lago Maracaibo, Venezuela; e Thamnodynastes dixoni do Llanos da Colômbia e Venezuela (Bailey et al., 2007).

Franco \& Ferreira (2002) descreveram uma espécie nova do Nordeste brasileiro, Thamnodynastes almae, e apresentaram dados de variação das espécies brasileiras. Esses autores também mencionaram cinco espécies novas, três que foram posteriormente descritas por Franco et al. (2003) (Thamnodynastes longicaudus) e por Bailey et al. (2005) (Thamnodynastes lanei e Thamnodynastes sertanejo); e duas espécies que permaneceram sem nome, Thamnodynastes sp.1 e Thamnodynastes sp. 2 (Franco \& Ferreira, 2002).

Atualmente são reconhecidas 19 espécies nominais distribuídas por todo o continente sulamericano, além de outras duas (Th. sp. 1 e Th. sp. 2) designadas no primeiro subitem dos Resultados. Dentre as Thamnodynastes, cinco são endêmicas dos tepuis da Venezuela, Th. chimanta, Th. corocoroensis, Th. duida, Th. marahuaquensis e Th. yavi; sendo que todas, exceto Th. chimanta, são conhecidas somente da sua série tipo.

\section{Tachymenis}

Em sua breve descrição do gênero, Wiegmann (1835) mencionou a afinidade de Tachymenis com Clelia pela presença de dentição opistóglifa em ambos. A espécie tipo, Tachymenis peruviana, foi descrita a partir de um único exemplar coletado no Peru por F.J. Meyer, sem localidade especificada (Wiegmann, 1835). Após sua descrição, o gênero Tachymenis passou a ter um conceito mais amplo nos catálogos do século XIX, abrigando espécies de serpentes das mais diversas regiões, como Conophis, Oxyrhopus, Erythrolamprus, entre outras, e conferindo ao nome uma ampla disseminação, porém sem real sentido biológico (Walker, 1945). Uma parte dessa confusão foi resolvida por Boulenger (1896), quando Tachymenis passou a ser utilizado somente para as formas sul-americanas, distribuídas na Bolívia, Chile e Peru.

Schlegel (1837), a partir de dois espécimes provenientes do Chile, descreveu Coronella chilensis, posteriormente proposta dentro do gênero Dipsas (Dúmeril \& Bribon, 1854). 
Fitzinger (1843) considerou Ta. peruviana no gênero Ophis, e Tschudi (1845) denominou Ta. peruviana como um subgênero de Ophis peruviana (nomen nudum). Girard (1854) alocou Coronella chilensis e Dipsas chilensis na sinonímia de Tachymenis chilensis, com localidade nas redondezas de Santiago, Chile. Nesta época, Girard definiu Tachymenis como composto por duas espécies, uma do Peru, descrita por Wiegmann, e sua forma chilena, Tachymenis chilensis (Girard, 1855).

Günther (1858) mencionou Tachymenis vivax e Ta. chilensis na família Coronellidae. Tachymenis vivax, na verdade, corresponde ao táxon Telescopus fallax (Colubridae) (Wallach et al., 2014), porém o autor diagnosticou Ta. chilensis corretamente. Com base em exemplares do Chile, Günther (1858) diagnosticou Ta. chilensis com sete supralabiais e faixa preta do olho ao ângulo da boca. Cope (1860) especificou Tachymenis para Ta. peruviana, Ta. chilensis e Tachymenis hypoconia, a última descrita nesse trabalho, com localidade tipo de Buenos Aires.

Jan (1863), ao estudar os Coronellidae, propõs o gênero Mesotes para a espécie de Schlegel, 1837 (Mesotes chilensis). O mesmo autor descreveu também uma nova espécie, Psammophylax assimilis (Jan, 1863), a qual foi posteriormente sinonimizada à Tachymenis peruviana assimilis por Donoso-Barros (1966). Boulenger (1896) redefiniu o gênero para incluir somente Ta. peruviana (com distribuição no Peru, Bolívia e Chile), colocando em sua sinonímia Coronella chilensis e P. assimilis, além de descrever Ta. affinis, com base em exemplares do Peru.

Philippi (1899) apontou que o número de espécies é na verdade muito maior do que relatado por autores anteriores, e nomeou outra espécie Coronella leucognatha (nomen nudum). Despax (1910) descreveu uma nova espécie, Tachymenis elongata, com localidade tipo para Tablazo de Payta, Peru. Barbour (1915), ao examinar 10 exemplares do Peru, descreveu uma espécie nova, Leimadophis andiculus, posteriormente alocada na sinonímia de Ta. peruviana (Walker, 1945). Dunn (1922) descreveu Tachymenis surinamensis para "Suriname", relacionando-a com Ta. elongata; contudo questionando se Tachymenis seria o gênero adequado (Dunn, 1922). Tachymenis surinamensis foi posteriormente sinonimizada à Philodryas elegans [Pseudalsophis elegans (Zaher et al., 2009a)] por Myers \& Hoogmoed (1974).

Paralelamente ao problema genérico, a grande variação de características morfológicas de Ta. peruviana, especialmente nos padrões de coloração, levou diversos autores à tentativas de categorizar tal diversidade em variedades ou subespécies. Werner $(1898 ; 1901 ; 1904)$ reconheceu cinco variedades: Tachymenis peruviana peruviana (Peru), Ta. p. vittata, Ta. p. 
coronellina, Ta. p. catenata (Chile), e Ta. p. dorsalis (Bolívia). Nos trabalhos de DonosoBarros da década de 60 e 70, Ta. chilensis passou para a sinonímia de Ta. peruviana, e quatro subespécies foram distinguidas: Ta. p. peruviana, Ta. p. chilensis, Ta. p. assimilis e Ta. p. melanura (Donoso-Barros, 1961; 1962; 1966; 1970).

O trabalho mais extenso de revisão do grupo é o de Walker (1945), no qual dividiu as espécies "afins" de Ta. peruviana em três complexos: "complexo peruviana" (Ta. peruviana, Ta. affinis e uma nova espécie, Tachymenis tarmensis); "complexo chilensis" (Ta. chilensis chilensis, Ta. c. assimilis e Ta. c. melanura); е о "complexo attenuata" (Ta. attenuata attenuata e Ta. a. boliviana). Walker (1945) forneceu também uma chave do gênero, excluindo contudo Ta. surinamensis (ainda válida na época) e Ta. elongata. O autor diferenciou Ta. peruviana das suas outras espécies pelos seguintes caracteres: do complexo attenuata pelo menor número de dentes maxilares ( 6 a 12; 12 a 16 em attenuata) e corpo mais robusto (alongado em attenuata); do complexo chilensis por apresentar 8 supralabiais e uma pré-ocular (7 supralabiais e 2 pré-oculares em chilensis) e pela presença de espinhos de mesmo tamanho no corpo do hemipênis (espinhos que aumentam de tamanho posteriormente no complexo chilensis); de Ta. affinis pela fórmula de dorsais 19-19-15 (17-17-15 em affinis); e de Ta. tarmensis (em parênteses) pela presença de fosseta apical (ausente), pelo menor número de dentes maxilares (12), fêmeas com menos de 50 subcaudais (mais de 50), e padrão manchado de coloração dorsal (padrão homogêneo escuro acinzentado ou amarronzado, sem manchas evidentes) (Walker, 1945).

Dentre os complexos de Walker (1945), o mais problemático e com menos informação permanece sendo o complexo attenuata. Walker (1945) descreveu Tachymenis attenuata attenuata baseado em dois exemplares originalmente depositados na Universidade de Arequipa, Peru, e sem localidade exata de coleta. Entretanto, o autor assumiu que a localidade seria Madre de Dios, na bacia Amazônica peruana (Schmidt \& Walker, 1943a; Walker, 1945). No mesmo trabalho a outra subespécie, Tachymenis attenuata boliviana, foi descrita com procedência de Incachaca no departamento de Cochabamba, Bolívia (2.500 m), e distinta de Ta. a. attenuata (em parênteses) por: 14-16 dentes maxilares (12-14), 152 ventrais (148-150), 69 subcaudais em machos (60-64); e padrão de coloração dorsal axadrezado (pintado) (Walker, 1945).

Subsequentemente, o trabalho de Ortiz (1973) esclareceu a situação taxonômica do "complexo chilensis", distinguindo as subespécies de Ta. chilensis e Ta. peruviana com base na contagem de escamas ventrais, subcaudais, pré-oculares, supralabiais e padrão de desenho dorsal. O autor restringiu Ta. chilensis à duas subespécies, Ta. chilensis chilensis e Ta. 
chilensis coronellina; recolocando Psammophylax assimilis na sinonímia de Ta. peruviana, conforme Boulenger (1896); e Ta. chilensis melanura na sinonímia de Ta. chilensis chilensis, como sua forma melânica (Ortiz, 1973).

Após Ortiz (1973), somente duas publicações trataram da taxonomia de Tachymenis. Pefaur et al. (1978) listaram as espécies de répteis de Arequipa, Peru, e caracterizaram Ta. peruviana por: comprimento rostro-cloacal máximo $550 \mathrm{~mm}, 145$ ventrais, 41 subcaudais e 19 dorsais; mencionando sua distribuição para regiões elevadas da região de "Arequipa, Chiguata, Salinas, Sumbay, Chuquibamba, etc." (Pefaur et. al., 1978). Miranda \& Couturier (1981) descreveram outra subespécie, Ta. peruviana yutoensis, com base no padrão dorsal de coloração de espécimes da Argentina, registros não mencionados previamente por Walker (1945) e Ortiz (1973).

\section{Tomodon}

O gênero Tomodon apareceu pela primeira vez em Duméril \& Bribon, 1853. Duméril, Bribon \& Duméril (1854) posteriormente descreveram Tomodon dorsatum, Tomodon lineatum e Tomodon ocellatus. O táxon To. lineatum passou à lista sinonímica de Conophis lineatus (Wallach et al., 2014). Boulenger (1886) separou To. dorsatus de To. ocellatus pela ausência de loreal e 17 fileiras de escamas na primeira, alterando a nomenclatura do epíteto específico de To.dorsatum Duméril, Bribon \& Duméril, 1854 para To.dorsatus.

Peters (1882) descreveu Opisthoplus degener, o qual foi sinonimizado à To. dorsatus por Boulenger (1896). Günther (1858) examinou um exemplar de To. dorsatus do Rio de Janeiro e o diagnosticou por: escamas dorsais em fileiras oblíquas, nasal única e longa, cabeça triangular, corpo alongado, coloração oliva com duas bandas marrons longitudinais ao longo do corpo e da cauda. Vanzolini (1947) descreveu Aproterodon clementi baseado em dois espécimes identificados como To. dorsatus do Rio Grande do Sul, distinguindo-a pela extrema redução do maxilar, forma das presas, forma simplificada do pterigóide e palatino, e pela dentição mandibular. Hoge (1959) redescreveu $O$. degener e a diagnosticou pela ausência de dentes maxilares (fora a presa). O mesmo autor sinonimizou A. clementi com $O$. degener, porém não diferenciou To. dorsatus. Peters \& Orejas-Miranda (1970) mantiveram a classificação de Hoge (1959), com O. degener válido, separando o último de To. dorsatus pelo maxilar extremamente reduzido, sem dentes anteriores às presas sulcadas aumentadas. Cechin (1989) analisou exemplares identificados como O. degener e encontrou uma variação de zero a dois no número de dentes maxilares pré-diastemais em uma mesma ninhada, registrando portanto uma variação de zero a cinco dentes maxilares em To. dorsatus. Dessa 
maneira a característica diagnóstica de $O$. degener passou a ser uma variação de To. dorsatus, sendo o primeiro alocado na sinonímia do último (Cechin, 1989).

\section{Pseudotomodon}

Leybold (1873) descreveu Pelias trigonatus com base em um exemplar de Mendonza, Argentina. Koslowsky (1896) descreveu pela primeira vez o gênero Pseudotomodon e a espécie Pseudotomodon mendozinus. Peracca (1897) descreveu Pseudotomodon crivelli diagnosticando-o como um tipo intermediário entre Tomodon e Philodryas. Amaral (1929) considerou o táxon de Leybold como uma subespécie de Tomodon ocellatus (To. ocellatus trigonatus). Bailey (1970) desconsiderou essa subespécie e sinonimizou P. mendozinus e $P$. crivelli à Pseudotomodon trigonatus, tornando o gênero monotípico.

\section{Gomesophis e Ptychophis}

O gênero Ptychophis e a espécie Pt.flavovirgatus foram descritos por Gomes (1915) com base em um exemplar de Santa Catarina, Brasil. Lema (1967) descreveu Paraptychophis meyeri com base em um único exemplar, diferenciando-a de Pt.flavovirgatus (em parênteses) por: ausência de diastema (presente); dentes maxilares $17(17+2)$; cabeça distinta do pescoço (levemente distinta); olhos menores; e uma pré-ocular (duas). Hoge \& Romano (1969) sinonimizaram o táxon de Lema (1967) ao de Gomes (1915) indicando que as diferenças encontradas são apenas uma variação de P. flavovirgatus (Porto \& Caramaschi, 1988).

Por sua vez, Gomesophis brasiliensis foi descrita como Tachymenis brasiliensis por Gomes (1918), sendo posteriormente alocada no gênero monotípico Gomesophis e separada de Tachymenis por características como formato e tamanho do osso pterigóide, formato da pupila e fórmula dentária (Hoge \& Mertens, 1959). Prudente (1993) revisou o gênero, utilizando dados morfométricos, merísticos, cranianos, hemipenianos e de história natural. Com base nos caracteres analisados a autora relacionou $G$. brasiliensis com o gênero Tachymenis (Prudente, 1993).

Gonzalez et al. (2014) descreveram a variação morfológica populacional de G. brasiliensis e P.flavovirgatus. Os autores sugeriram que a semelhança morfológica desses dois táxons, relacionada às características adaptativas de uso de hábitats aquáticos, é indicativa da proximidade filogenética dos mesmos, e citam que tais características foram utilizadas como justificativas para a sinonimização dos mesmos, proposta na tese de Franco (2000).

\section{Calamodontophis}

Gênero descrito por Amaral (1935) como Calamodon paucidens, sendo posteriormente alterado para Calamodontophis por tratar-se de um nome previamente ocupado (Amaral, 1963). Amaral (1935) relacionou o seu novo gênero com Tomodon, distinguindo-o pelo 
menor diâmetro da região cervical e cefálica em relação ao corpo. Posteriormente, Bailey (1966a) reavaliou a descrição de Amaral (1935), fornecendo a seguinte diagnose corrigida e ampliada: 7+2 dentes maxilares, seis dentes palatinos e 10 pterigóideos; 135 ventrais; escama cloacal dividida; 32 subcaudais; sete supralabiais ( $3^{\mathrm{a}}$ e $4^{\mathrm{a}}$ em contato com olho); nasal inteira; escamas dorsais lisas com 15 fileiras contínuas e uma fosseta apical.

Pagini \& Lema (1987) encontraram o segundo exemplar da espécie e corrigiram e complementaram, por sua vez, o trabalho de Bailey (1966a). Estes autores identificaram também uma característica importante, a coloração escura (preta) da mucosa oral e cloacal (Pagini \& Lema, 1987; Franco et al., 2006). Franco et al. (2006) descreveram a segunda espécie, C.ronaldoi, a partir de dois exemplares do Paraná; e a diferenciaram de C.paucidens pelo padrão de coloração dorsal na primeira, com a presença de uma linha longitudinal dorsal clara, uma mancha escura da comissura da boca até a região gular, e uma mancha preta nas parietais (Franco et al., 2006).

Outros poucos trabalhos forneceram informações desse gênero extremamente raro, sendo toda a informação restrita a poucos exemplares (Franco et al., 2001; Carreira \& Meneguel, 2004; Carreira et al., 2005; Carreira \& Lombardo, 2008; Carreira \& Maneyro, 2015). 


\section{CONCLUSÕES}

- A tribo Tachymenini foi recuperada como monofilética, sustentada por alto suporte de dados morfológicos e moleculares, sendo a viviparidade a única sinapomorfia da tribo;

- Não foi encontrado suporte para o posicionamento da tribo dentro de Xenodontinae;

- O uso combinado de dados morfológicos e moleculares foi fundamental para o entendimento das relações filogenéticas da tribo;

- Com base no levantamento de dados morfológicos, as seguintes decisões taxonômicas foram propostas para Tachymenini, anteriormente às analises filogenéticas: sinonimização de Thamnodynastes ceibae à Thamnodynastes dixoni; sinonimização de Tachymenis elongata à Pseudalsophis elegans; alocação de Thamnodynastes hypoconia como sinônimo júnior de Thamnodynastes strigatus; Thamnodynastes nattereri considerada como espécie plena, sendo necessária a designação de um neótipo; e descrição de Thamnodynastes phoenix sp. nov. para as populações de Thamnodynastes do Cerrado e Caatinga da região central e Nordeste do Brasil;

- As análises filogenéticas de dados moleculares e morfológicos permitiram as seguintes conclusões:

1) O gênero Thamnodynastes é restrito para as espécies do grupo pallidus (Th. pallidus, Th. sertanejo, Th. longicaudus e uma quarta espécie não descrita) e Th. lanei;

2) O gênero Dryophylax é revalidado para alocar todas as espécies de Thamnodynastes com 19 fileiras de dorsais (quilhadas ou lisas), além de Thamnodynastes chimanta e Thamnodynastes duida, com 17 dorsais;

3) As espécies Th. duida, Th. corocoroensis, Th. marahuaquenis, Th. ramonriveroi e Th. yavi, apesar de não terem sido incluídas nas análises filogenéticas por carência de dados disponíveis, são alocadas junto às espécies presumidamente mais próximas (Th. paraguanae, Th. gambotensis, Th. dixoni e Th. chimanta) e, portanto, posicionadas tentativamente no gênero Dryophylax;

4) Thamnodynastes sp. (complexo "hypoconia" sensu Cei et al., 1992) é também alocada no gênero Dryophylax, e duas espécies são reconhecidas para o que anteriormente era considerado como "Thamnodynastes hypoconia": Dryophylax sp.1 e Dryophylax sp.2, da região Sul do Brasil e Argentina e da região central do Brasil, respectivamente;

5) O gênero Mesostes é revalidado para abrigar as espécies de Thamnodynastes do grupo strigatus (Th.rutilus e Th. strigatus); 
6) Thamnodynastes sp. nov. (aff. strigatus), de um enclave de área aberta na Amazônia Peruana, é tentativamente alocada no gênero Mesostes, pendente da disponibilidade de mais dados;

7) Tachymenis affinis é alocada em um gênero a parte, Gen. Nov. 1, com base em características hemipenianas e cranianas, e pelo seu posicionamento nas árvores filogenéticas;

8) Tomodon ocellatus e Pseudotomodon trigonatus são alocadas no gênero Tachymenis, com alto suporte molecular e morfológico;

9) O gênero Tachymenis é dividido em dois grupos bem sustentados por dados moleculares e morfologia hemipeniana: clado peruviana (Ta. peruviana, Ta. ocellata e Ta. trigonata) e clado chilensis (Ta. chilensis e Ta.attenuata);

10) Tachymenis tarmensis é mantida dentro do gênero Tachymenis, porém seu posicionamento está ainda pendente da disponibilidade de dados;

11) Tomodon orestes é alocada em um gênero a parte, Gen. Nov. 2, este mais proximamente relacionado ao gênero Calamodontophis;

12) O gênero Tomodon fica restrito para Tomodon dorsatus, diagnosticado por características cranianas e de morfologia externa;

- Para os 33 táxons da tribo Tachymenini anteriormente válidos, 14 são mantidos, 17 são realocados de gênero e dois são invalidados;

- A nova composição de Tachymenini passa a abranger 10 gêneros e 35 espécies: Calamodontophis paucidens, Calamodontophis ronaldoi, Gomesophis brasiliensis, Ptychophis flavovirgatus, Tachymenis attenuata, Tachymenis chilensis, Tachymenis ocellata nov. comb., Tachymenis peruviana, Tachymenis tarmensis, Tachymenis trigonata nov. comb., Gen. Nov. 1 affinis nov. comb., Thamnodynastes lanei, Thamnodynastes longicaudus, Thamnodynastes pallidus, Thamnodynastes sertanejo, Dryophylax almae nov. comb., Dryophylax chaquensis nov. comb., Dryophylax chimanta nov. comb., Dryophylax corocoroensis nov. comb., Dryophylax dixoni nov. comb., Dryophylax duida nov. comb., Dryophylax gambotensis nov. comb., Dryophylax marahuaquensis nov. comb., Dryophylax nattereri nov. comb., Dryophylax paraguanae nov. comb., Dryophylax phoenix sp. nov. nov. comb., Dryophylax ramonriveroi nov. comb., Dryophylax sp.1 sp. nov., Dryophylax sp.2 sp. nov., Dryophylax yavi nov. comb., Mesostes rutilus nov. comb., Mesostes strigatus nov. comb., Mesostes sp. nov, Tomodon dorsatus e Gen. Nov. 2 orestes nov. comb.; 
- Além dessas novas propostas classificatórias, as análises filogenéticas permitiram reconhecer três complexos de espécies crípticas em Tachymenini: Dryophylax nattereri, Dryophylax sp. (complexo “hypoconia” sensu Cei et al., 1992) e Mesostes strigatus;

- Cinco outras espécies candidatas são elencadas para a tribo: duas no complexo de Dryophylax sp. (complexo "hypoconia" sensu Cei et al., 1992), uma para o complexo de Dryophylax nattereri, uma no complexo de Mesostes strigatus e uma quarta espécie de Thamnodynastes do grupo pallidus;

- A diversidade dentro de Tachymenini, especialmente para o gênero Thamnodynastes (lato sensu), é ainda subestimada, e maiores esforços são necessários para melhor diagnosticar as linhagens evolutivas crípticas recuperadas dentro dos gêneros Dryophylax e Mesostes; 


\section{RESUMO}

Apesar do crescente aporte de informações na sistemática das serpentes Neotropicais, impulsionado pelo desenvolvimento de técnicas moleculares, as relações evolutivas intra e intertribais da subfamília Xenodontinae ainda são incipientes, e o posicionamento de gêneros e espécies de várias de suas tribos é desconhecido. A tribo Tachymenini (Dipsadidae, Xenodontinae) abriga sete gêneros e 33 espécies válidas, amplamente distribuídas na América do Sul, e representadas por um complexo histórico taxonômico e uma diversidade subamostrada. O presente projeto visou estudar as relações evolutivas de Tachymenini, de modo a testar as hipóteses de relacionamento entre seus gêneros e espécies em um contexto integrativo, e assim validar mudanças taxonômicas. Todos os táxons válidos de Tachymenini foram examinados, sendo este o trabalho mais abrangente para a tribo. Foram realizadas análises filogenéticas de Máxima Parcimônia, Máxima Verossimilhança e Bayeasiana, a partir da codificação de 70 caracteres morfológicos e do sequenciamento de três genes mitocondriais e três nucleares. As análises filogenéticas recuperaram Tachymenini como monofilética e seus gêneros mais especiosos, Tachymenis, Thamnodynastes e Tomodon, polifiléticos. Dois novos gêneros e quatro novas espécies são propostas, três espécies são sinonimizadas e dois outros gêneros são revalidados, resultando em uma nova classificação com 10 gêneros e 35 espécies para a tribo. Ainda, três complexos de espécies crípticas foram recuperados, o que aumentaria a diversidade de Tachymenini em pelo menos quatro novas espécies. $\mathrm{O}$ uso de dados morfológicos e moleculares combinados foi fundamental para o melhor entendimento das relações entre os gêneros da tribo, e para o estabelecimento de caracteres diagnósticos. Outros tipos de abordagens, além de complementação de lacunas amostrais, tanto morfológicas quanto moleculares, são necessárias em estudos sistemáticos futuros de Tachymenini e outros grupos de xenodontíneos. 


\section{ABSTRACT}

In spite of the incoming flow of information regarding the systematics of Neotropical snakes, largely driven by the innovation of new techniques for molecular data, the evolutionary relations among members of the subfamily Xenodontinae are incipient, and the phylogenetic status of several genera and species are still unknown. The tribe Tachymenini (Dipsadidade, Xenodontinae) is composed by seven genera and 33 species widely distributed throughout South America, and characterized by a complex taxonomic history and a hidden diversity. This project aimed to study the phylogenetic relations of Tachymenini, testing the evolutionary hypotheses of relationships among its genera and species in an integrative approach, and to further validate taxonomic changes. All Tachymenini taxa were analyzed in the most comprehensive study of the tribe. Maximum Parsimony, Maximum Likelihood and Bayesian analysis were performed using 70 morphological characters, three mitochondrial and three nuclear genes. Phylogenetic analysis recovered Tachymenini as monophyletic, and its most specious genera, Tachymenis, Thamnodynastes and Tomodon, as polyphyletic. Two new genera and four new species are proposed, three species are synonymized, and two other genera are resurrected, resulting in a new composition of 10 genera and 35 species for the tribe. Nevertheless, three cryptic species complexes were recovered, which would increase the diversity for Tachymenini in at least four other species. The combined use of morphological and molecular data was fundamental for a better understanding of the genera relationships, and for the establishment of diagnostic characters for the taxa. Other approaches, along with the improvement of morphological and molecular data deficiencies, are necessary in future systematic studies of Tachymenini and other Xenodontinae. 


\section{REFERÊNCIAS BIBLIOGÁFICAS}

Abuys, A. 1986. The snakes of Surinam, Part XV, Subfamily Xenodontinae (genera Tantilla, Thamnodynastes, and Tripanurgos). Litteratura Serpentium, 6(3): 107-116.

Akmentins, M. S.; Vaira, M. 2010. Reptilia, Squamata, Dipsadidae, Tomodon orestes Harvey and Muñoz, 2004: Distribution extension, new country record. Check List, 6(2): 248249.

Akmentins, M. S.; Pereyra, L. C. 2010. Thamnodynastes chaquensis Bergna y Alvarez, 1993 (Squamata, Dipsadidae). Primer Registro Para La Provincia De Jujuy (República Argentina). Cuad. Herpetol., 24(11): 63-64.

Albuquerque, N. R.; D'Agostini, F. M. 2000. Análise comparativa do crânio de Imantodes cenchoa Linnaeus 1758 e I. lentiferus Cope 1894 (Serpentes, Colubridae). Bol. Mus. Par. Emilio Goeldi, Zool., 16(2): 135-151.

Albuquerque, N. R.; Lema, T. 2008. Taxonomic revision of the Neotropical water snake Hydrops triangularis. Zootaxa, 1685:55-66.

Amaral, A. 1926. Notas de ophiologia. $1^{\text {a }}$ nota de ophiologia. Sobre a invalidez de um gênero e algumas espécies de ofídios sul-americanos. Rev. Mus. Paulista, 14:17-33.

Amaral, A. 1929. Contribuição ao conhecimento dos ophidios do Brasil. IV. Lista remissiva dos ophidios do Brasil. Mem. Inst. Butantan, 4: 102.

Amaral, A. 1930. Studies of neotropical Ophidia XVI. Two new snakes from Central Colombia. Bull. Antiv. Inst. Am., 4:27-28.

Amaral, A. 1935. Contribuição ao conhecimento dos ophidios do Brasil. VII. Novos gêneros e espécies de colubrídeos opistoglyphos. Mem. Inst. Butantan, 9: 203-206.

Amaral, A. 1944. Notas sobre a ofiologia neotrópica e brasílica. IX. Formas de boigineos de recente registro. Pap. Avul. Zool., 5: 65-74.

Amaral, A. 1963. Herpetological note. Copeia, 3: 580.

Amaral, A. 1978. Serpentes do Brasil. Iconografia Colorida. 2a Ed. Melhoramentos EDUSP, São Paulo, 247 pp.

Andersson, L. G. 1899. Catalogue of Linnean type-specimens of snakes in the Royal Museum in Stockholm. Bihang Till Koeniger Svenska Vetenskaps-Akademiens Handlingar, 24(4): 1-35.

Angarita M. O.; Montes-Correa, A. C.; Renjifo, J. M. 2015. Amphibians and reptiles of an agroforestry system in the Colombian Caribbean. Amph. Rept. Conserv., 8(20): 19-38.

Araújo, C.O.; Condez, T. H.; Bovo, R. P.; Centeno, F. C.; Luiz, A. M. 2010. Anfíbios e 
répteis do Parque Estadual Turístico do Alto Ribeira (PETAR), SP: um remanescente de Mata Atlântica do Sudeste do Brasil. Biota Neotrop., 10(4): http://www.biotaneotropica.org.br/v10n4/pt/abstract?inventory+bn01710042010.

Arevalo, E.; Davis, S. K.; Sites, J. W. J. 2009. Mitochondrial DNA Sequence Divergence and Phylogenetic Relationships among Eight Chromosome Races of the Sceloporus grammicus Complex ( Phrynosomatidae ) in Central Mexico. Syst. Biol., 43: 387-418.

Avila, L. J. 2009. Reptilia, Squamata, Dipsadidae, Pseudotomodon trigonatus (Leybold, 1873): Distribution extension. Check List, 5(3): 391-393.

Bailey, J. R. 1966a. A redescription of the snake Calamodontophis paucidens. Copeia, 4:8856.

Bailey, J. R. 1966b. Modes of evolution in new world opistoglyph snakes. Mem. Inst. Butantan, 53: 67-72.

Bailey, J. R. 1967. The Synthetic Approach to Colubrid Classification. Herpetologica, 23(2): 155-161.

Bailey, J. R. 1970. Pseudotomodon. Pp. 256. In Catalogue of the Neotropical Squamata, Part I: Snakes. J. A. Peters and B. Orejas-Miranda (eds.). Smithsonian Institution, Washington, D.C.

Bailey, J. R. 1981. Notes on the genus Thamnodynastes. $1^{\circ}$ Simpósio Internacional sobre Serpentes em Geral e Artrópodos Peçonhentos, Sao Paulo, Brazil. Abstract.

Bailey, J. R.; Thomas, R. A.; Silva Jr. N. J. 2005. A revision of the South American genus Thamnodynastes Wagler, 1830 (Serpentes, Colubridae, Tachymenini). I. Two new species of Thamnodynastes from Central Brazil and adjacent areas, with redefinition of and neotype designation for Thamnodynastes pallidus (Linnaeus, 1758). Phyllomedusa, 4(2): 83-101.

Bailey, J. R.; Thomas, R. A. 2007. A revision of the South American snake genus Thamnodynastes Wagler, 1830 (Serpentes: Colubridae, Tachymenini). II. Three new species from northern South America, with further desciptions of Thamnodynastes gambotensis Pérez-Santos and Moreno and Thamnodynastes ramonriveroi Manzanilla and Sánchez. Mem. Fund. La Salle Cienc. Nat., 166: 7-27.

Barbour, T. 1915. A new snake from Southern Peru. Proc. Biol. Soc. Wash., 28:149-150.

Bauer, A. M; Parham, J. F.; Brown, R. M.; Stuart, B. L.; Grismer, L.; Papenfuss, T. J.; Böhme, W.; Savage, J. M.; Carranza, S.; Grismer, J. L.; Wagner, P.; Schmitz, A. Ananjeva, N.; Inger, R. F. 2011. Availability of new Bayesian-delimited gecko names 
and the importance of character-based species descriptions. Proc. R. Soc. B., 278: 490492.

Bellagamba, P. J.; Vega, L. E. 1996. Thamnodynastes hypoconia. Distribution. Herp. Rev., 27(1):36.

Bellairs, A.; Kamal, A. M. 1981. The chondocranium and the development of the skull in recente reptiles. Pp 1-263. In: Biology of the Reptilia, Vol.11, Morphology F. C. Gans and T. S. Parsons (eds.). Academic Press, London.

Bellini, G. P.; Arzamendia, V.; Giraudo, A. R. 2013. Ecology of Thamnodynastes hypoconia In Subtropical-Temperate South America. Herpetologica, 69(1): 67-79.

Bellini, G. P.; Giraudo, A. R.; Arzamendia, V. 2014. Comparative ecology of three species of Thamnodynastes (Serpentes, Dipsadidae) in subtropical-temperate South Am. J. Herpetol., 24: 87-96.

Bernarde, P. S.; Albuquerque, S.; Barros, T. O.; Turci, L. C. B. 2012. Snakes of Rondônia $\begin{array}{llll}\text { State, } & \text { Brazil. } & \text { Biota }\end{array}$ http://www.biotaneotropica.org.br/v12n3/en/abstract?inventory+bn00412032012.

Bernarde, P. S.; Kokobum, M. N. C.; Marques, O. 2000a. Utilização de hábitat e atividade em Thamnodynastes strigatus (Günther, 1858) no sul do Brasil (Serpentes, Colubridae).

Bol. Mus. Nac., N.S., Zool., 428: 1-8.

Bernarde, P. S.; Moura-Leite, J. C.; Machado, R. A.; Kokobum, M. N. C. 2000b. Diet of The Colubrid Snake, Thamnodynastes strigatus (Günther, 1858) From Paraná State, Brazil, With Field Notes On Anuran Predation. Rev. Brasil. Biol., 60(4): 695-699.

Bernardo, P. H.; Machado, F. A.; Murphy, R. W.; Zaher, H. 2012. Redescription and morphological variation of Oxyrhopus clathratus Duméril, Bibron and Duméril, 1854 (Serpentes: Dipsadidae: Xenodontinae). South Am. J. Herpetol., 7(2): 134-148.

Bergna, S.; Alvarez, B. 1993. Descripción de una nueva especie de Thamnodynastes (Reptilia: Serpentes, Colubridae) del nordeste argentino. Facena, 10: 5-18.

Bickford, D.; Lohman, D. J.; Sodhi, N. S.; Ng, P. K.; Meier, R.; Winker, K.; Ingram, K. K.; Das, I. 2007. Cryptic species as a window on diversity and conservation. Trends Ecol. Evol., 22: 148-155.

Bizerra, A. F.; Marques, O. A. V.; Sazima, I. 2005. Reproduction and feeding of the colubrid snake Tomodon dorsatus from southeastern Brazil. Amphibia-Reptilia, 26: 33-38.

Blackburn, D. G. 1985. Evolutionary Origins of Viviparity in the Reptilia. II. Serpentes, Amphisbaenia, and Ichthyosauria. Amphibia-Reptilia, 6: 259-291.

Bogert, C. M. 1947. The status of the genus Leptodrymus Amaral, with comments on 
modifications of colubrid premaxillae. Am. Mus. Nov., 1352:1-14.

Boos, H. 2001. The snakes of Trinidad \& Tobago. Texas A\&M Univ. Press, College Station. 328 pp.

Bouckaert, R.; Heled, J.; Kühnert, D.; Vaughan, T.; Wu, C-H.; Xie, D.; Suchard, M. A.; Rambaut, A.; Drummond, A. J. 2014. BEAST 2: A Software Platform for Bayesian Evolutionary Analysis. PLoS Comput. Biol., 10(4): e1003537. doi:10.1371/journal.pcbi.1003537.

Boulenger, G. A. 1885. A list of Reptiles and Batrachians from the Province Rio Grande do Sul, Brazil, sento to the Natural History Museum by Dr. H. von Ihering. Ann. Mag. Nat. Hist., serie 5, 15: 191-196.

Boulenger, G. A. 1886. A synopsis of the Reptiles and Batrachians of the Province Rio Grande do Sul, Brazil. Ann. Mag. Nat. Hist., serie 5, 18: 423-445.

Boulenger, G. A. 1896. Catalogue of the snakes in the British Museum (Natural History). Vol.III. London, British Museum (Natural History), xiv + 727 pp.

Brongersma, L. D. 1940. Snakes from the leeward group, Venezuela and Eastern Colombia. Pp. 115-137. In: P. W. Hummelinck. Studies on the fauna of Curacao, Aruba, Bonaire and the Venezuelan Islands. M. Nijhoff, The Hague. 2 vols.

Burbrink, F. 2005. Inferring the phylogenetic position of Boa constrictor among the Boinae. Mol. Phylog. Evol., 34: 167-180.

Burbrink, F. T.; Lawson, R.; Slowinski, J. B. 2000. Mitochondrial DNA phylogeography of the polytypic North American rat snake (Elaphe obsoleta): a critique of the subspecies concept. Evolution, 54: 2107-2118.

Cacivo, P. M. 1997. Thamnodynastes hypoconia. Distribution. Herp. Rev., 28(3): 160.

Cadle, J. E. 1984a. Molecular systematics of Neotropical xenodontine snakes: I. South American xenodontines. Herpetologica, 40: 8-20.

Cadle, J. E. 1984b. Molecular systematics of xenodontine colubrid snakes. III. Overview of xenodontine phylogeny and the history of New World snakes. Copeia, 1984: 641-652.

Cadle, J. E. 1984c. Molecular systematics of xenodontine colubrid snakes. III. Overview of xenodontine phylogeny and the history of New World snakes. Copeia, 1984(3): 641652.

Cadle, J. E. 1988. Phylogenetic relationships among advanced snakes. A molecular perspective. Univ. California Publ. Zoo., 119ï-x + 1-77. 
Cadle, J. E. 1994. The Colubrid radiation in Africa (Serpentes: Colubridae): phylogenetic relationship and evolutionary patterns based on immunological data. Zool. J. Linn. Soc., 110: 103-140.

Cadle, J. E.; Greene, H. W. 1993. Phylogenetic patterns, biogeography, and the ecological structure of Neotropical snake assemblages. Pp. 281-293. In: Species diversity in ecological communities: Historical and geographical perspective. R. E. Ricklefs and D. Schluter (eds.). University of Chicago Press, Chicago.

Camargo, A.; Morando, M.; Avila, L. J.; Sites, J. W. 2012. Species delimitation with ABC and other coalescent-based methods: A test of accuracy with simulations and an empirical example with lizards of the Liolaemus darwinii complex (Squamata: Liolaemidae). Evolution, 66: 2834-2849.

Carreira, S.; Brazeiro, A.; Camargo, A.; Rosa, I.; Canavero, A.; Maneyro, R. 2012. Diverstity of reptiles of Uruguai: knowledge and information gaps. Bol. Soc. Zool., Uruguay $\left(2^{\mathrm{a}}\right.$ época), 21 (1-2): 9-29.

Carreira, S.; Lombardo, I. 2008. The Hemipenis and External Morphology of a New Specimen of Calamodontophis paucidens (Amaral, 1935) (Serpentes: Colubridae, Dipsadinae, Tachymenini) from Uruguay. Herp. Rev., 39(3): 282-283.

Carreira, S.; Maneyro, R. 2015. Lista Roja de los Anfibios y Reptiles del Uruguay. Una evaluación del estado de conservación de la herpetofauna de Uruguay sobre la base de los criterios de la Unión Internacional para la Conservación de la Naturaleza. Dirección Nacional de Medio Ambiente, Montevideo. 64 pp.

Carreira, S.; Meneghel, M. D. 1999. Dados de comportamiento de Calamodontophis paucidens (Amaral, 1935) (Squamata, Ophidia) en cautiverio. V Congreso Latinoamericano de Herpetología. Publ. Extra, Mus. Nac. Hist. Nat., Montevideo, $50: 44$.

Carreira, S.; Meneghel, M. D. 2004. Morfología externa de ejemplares uruguayos de Calamodontophis paucidens (Amaral, 1935) (Squamata, Ophidia). Bol. Soc. Zool., Uruguay, 2a. época, 14:32-35.

Carreira, S.; Meneghel, M. D.; Achaval, F. 2005. Reptiles de Uruguay. Seción Zoologia Vertebrados. Facultad de Ciencias, Motevideo, Uruguay. 639 pp.

Carrillo de Espinoza, N.; Icochea, J. 1995. Lista taxonómica preliminar de los reptiles vivientes del Peru. Publ. Mus. Hist. Nat. Univ. Mayor San Marcos (A, Zool) 49: 127.

Castoe, T. A.; de Koning, A. P. J.; Kim, H.; Gu, W.; Noonan, B. P.; Naylor, G.; Jiang, Z. J.; 
Parkinson, C. L.; Pollock, D. D. 2009. Evidence for an ancient adaptive episode of convergent molecular evolution. PNAS, 106(22): 8986-8991.

Cei, J. M. 1993. Reptiles del noroeste, nordeste y este de la Argentina. Herpetofauna de las selvas subtropicales, puna y pampas. Boll. Mus. Reg. Scien. Nat. Torino., Monografia XIV. 949 pp.

Cei, J. M.; Bergna, S.; Alvarez, B. 1992. Nueva combinación para el gênero Thamnodynastes (Serpentes, Colubridae) de Argentina. Facena, 9:123-134.

Cechin, S. T. Z. 1989. Opisthoplus degener Duméril, Bribon \& Duméril, 1854, um sinônimo sênior de Tomodon dorsatus Peters, 1882 (Serpentes, Colubridae, Tachymeninae). Com. Mus. Ciênc. PUC-RS, sér. Zool., 2(11): 203-210.

Centeno, F. C., Sawaya, R. J.; Marques, O. A. V. 2008. Snake assemblage of Ilha de São Sebastião, southeastern Brazil: comparison to mainland. Biota Neotrop. 8(3): http://www.biotaneotropica.org.br/v8n3/en/abstract?article+bn00608032008.

Chávez, G. 2012. Tachymenis affinis Boulenger, 1896 (Squamata: Colubridae): Distribution extension in Peru. Herpetotropicos, 7(1-2): 31-33.

Coelho, R. D. F.; Souza, K.; Weider, A. G.; Pereira, L. C. M.; Ribeiro, L. B. 2013. Overview of the distribution of snakes of the genus Thamnodynastes (Dipsadidae) in northeastern Brazil, with new records and remarks on their morphometry and pholidosis. Herp. Notes, 6:355-360.

Cole, C. J.; Townsend, C. R.; Reynolds, R. P.; MacCulloch, R. D.; Lathrop, A. 2013. Amphibians and reptiles of Guyana, South America: illustrated keys, annotated species accounts, and a biogeographic synopsis. Proc. Biol. Soc. Was., 125(4): 317-620.

Conrad, J. L. 2008. Phylogeny and systematics of Squamata (Reptilia) based on morphology. Bull. Am. Mus. Nat. Hist., 310: 182 pp.

Cope, E. D. 1860. Catalogue of the Colubridae in the Museum of the Academy of Natural Sciences of Philadelphia, with notes and descriptions of new species. Part 2. Proc. Acad. Nat. Sci. Phil., 1864:166-181.

Cope, E. D. 1887. Synopsis of the Batrachia and Reptilia obtained by H. II. Smith, in the Province of Mato Grosso, Brazil. Proc. Am. Philos. Soc., 24: 44-60.

Cope, E. D. 1892. The osteology of the Lacertilia. Proc. Am. Philos. Soc., 13:185-221.

Cope, E. D. 1895. The classification of the Ophidia. Trans. Am. Zool. Soc. (Series 2) (1894), 18(3): 186-219.

Cordeiro, C. L.; Hoge, A. R. 1973. Contribuição ao conhecimento das serpentes do estado de Pernambuco. Mem. Inst. Butantan, 37: 261-290. 
Cracraft, J. 1983. Species concepts and speciation analysis. Curr. Ornithol., 1: 159-187.

Cundall, D.; Irish, F. 2008. The snake skull. Pp. 349-692. In: Biology of the Reptilia, Vol. 20, Morphology H. C. Gans, A. S. Gaunt, and K. Adler (eds.). Society for the Study of Amphibians and Reptiles, Ithaca, NY.

Curcio, F. F.; Nunes, P. M. S.; Harvey, M. B.; Rodrigues, M. T. 2011. Redescription of Apostolepis longicaudata (Serpentes: Xenodontinae) with Comments on Its Hemipenial Morphology and Natural History. Herpetologica, 67: 318-331.

Davis, J. I.; Nixon, K. C. 1992. Populations, genetic variation, and the delimitation of phylogenetic species. Syst. Biol., 41: 421-435.

Despax, R. 1910. Mission géodésique de l'Équateur. Collections recueillies par M. le Dr. Rivet. Liste des ophidiens et descriptions des espèces nouvelles. (Note préliminaire). Bull. Mus. Natl. Hist. Nat. Paris, 16: 368-376.

DiPietro, D. O.; Alcalde, L.; Williams, J. D. 2014a. New cranial characters in the tribe Hydropsini (Serpentes: Dipsadidae: Xenodontinae). Acta Herpetol., 9(1): 1-14.

DiPietro, D. O.; Alcalde, L.; Williams, J. D. 2014b. Nasal cartilages, hyobranchial apparatus, larynx, and glottal tubes in four species of Hydropsini (Serpentes: Dipsadidae: Xenodontinae). Vertebrate Zool., 64(1):103-111.

Dixon, J. R. 1980. The Neotropical colubrid snake genus Liophis: The generic concept. Milwaukee Publ. Mus. Contr. Biol. Geol., 31: 1-40.

Dixon, J. R.; Soini, P. 1977. The reptiles of the Upper Amazon Basin, Iquitos Region, Peru. II. Crocodilians, turtles, and snakes. Milwaukee Public Museum, Contr. Biol. Geol., 12: $1-91$.

Dixon, J. R.; Soini, P. 1986. The reptiles of the Upper Amazon Basin, Iquitos Region, Peru. Part 1, Lizards and amphisbaenians. Part 2, Crocodilians, turtles and snakes. Milwaukee Public Museum, Milwaukee. 154 pp.

Domingos, F. M. C. B.; Colli, G. R.; Lemmon, A.; Lemmon, E. M.; Beheregaray, L. B. 2016 (2017). In the shadows: Phylogenomics and coalescent species delimitation unveil cryptic diversity in a Cerrado endemic lizard (Squamata: Tropidurus). Mol. Phylog. Evol., 107: 455-465. http://dx.doi.org/10.1016/j.ympev.2016.12.009.

Donoso-Barros, R. 1961. The Reptiles of the Lund University Chile Expedition. Copeia, $4: 486-488$.

Donoso-Barros, R. 1962. Los ofídios chilenos. Not. Mem. Mus. Nac. Hist. Nat. Chile, 66: 38.

Donoso-Barros, R. 1966. Reptiles de Chile. Santiago: Univ. Chile, 458 pp. 
Donoso-Barros, R. 1970. Catálago herpetológico chileno. Bol. Mus. Nac. Hist. Nat. Chile, 31: 49-124.

Dowling, H. G. 1951. A proposed method of expressing scale reductions in snakes. Copeia 1951: 131-134.

Dowling, H. G. 1967. Hemipenes and Other Characters in Colubrid Classification. Herpetologica, 23(2):138-142.

Dowling, H. G.; Duellman, W. E. 1978. Systematic herpetology: a synopsis of families and higher categories. Herpetological Information Search Systems Publications, New York. vii +240 pp.

Dowling, H. G.; Hass, C. A.; Hedges, S. B.; Highton, R. 1996. Snake relationships revealed by slow evolving proteins: a preliminary survey. J. Zool., 240: 1-28.

Dowling, H. G.; Highton, R.; Maha, G. C.; Maxson, L. R. 1983. Biochemical evaluation of colubrid snake phylogeny. J. Zool., 201: 309-329.

Duméril, A. M. C.; Bribon, G.; Duméril, A. 1854. Erpétologie générale ou histoire naturelle complete des reptiles. Paris, Librairie Encyclopédique de Roret, v.7.

Dunn, E. R. 1922. Two new South American snakes. Proc. Biol. Soc. Washington, 35: 219220.

Dunn, E. R. 1928. A tentative key arrangement of the American genera of Colubridae. Bull. Antivenim Inst. Amer, 2: 18-24.

Estes, R.; de Queiroz, K.; Gauthier, J. 1988. Phylogenetic relationships within Squamata. Pp. 119-281 In: Phylogenetic relationships of the lizard families. R. Estes and G. Pregill (eds.). Stanford University Press, Palo Alto, CA.

Ferrarezzi, H. 1993a. Sistemática filogenética de Elapomorphus, Phalotris e Apostolepis (Serpentes: Colubridae: Xenodontinae). Dissertação (Mestrado) Instituto de Biociências da Universidade de São Paulo. São Paulo, 276 pp.

Ferrarezzi, H. 1993b. Nota sobre o gênero Phalotris com revisão do grupo nasutus e descrição de três novas espécies (Serpentes, Colubridae, Xenodontinae). Mem. Inst. Butantan, 55 (supl.1): 21-38.

Ferrarezzi, H. 1994. Uma sinopse dos gêneros e classificação das Serpentes (Squamata) II. Família Colubridae. Pp. 81-91. Em: Herpetologia no Brasil, 1. Nascimento, L. B. et al. (eds.). PUC-MG. Fundação Biodiversitas e Fundação Ezequiel Dias, Belo Horizonte.

Figueroa, A.; McKelvy A. D.; Grismer L. L.; Bell C. D.; Lailvaux, S. P. 2016. A SpeciesLevel Phylogeny of Extant Snakes with Description of a New Colubrid Subfamily and Genus. PLoS ONE 11(9): e0161070. doi:10.1371/journal.pone.0161070. 
Fitzinger, L. 1843. Sistema Reptilium. Fasciculus Primus. Amblyglossae. Braumüller et Seidel Bibliopolas, Vienna. vi + 106 pp.

Fortes, V. B.; Lucas, E. M.; Caldart, V. M. 2010. Reptilia, Serpentes, Dipsadidae, Gomesophis brasiliensis (Gomes, 1918): Distribution extension in state of Santa Catarina, Brazil. Check List, 6 (3): 414-415.

Franco, F. L. 2000 (1999). Relações filogenéticas entre os gêneros da tribo Tachymenini Bailey, 1967 (Serpentes, Colubridae). Tese (Doutorado). Departamento de Biociências da Universidade de São Paulo. São Paulo, 252 pp.

Franco, F. L.; Ferreira, T. G. 2002. Descrição de uma nova espécie de Thamnodynastes Wagler, 1830 (Serpentes, Colubridae) do nordeste brasileiro, com comentários sobre o gênero. Phyllomedusa, 1(2): 57-74.

Franco, F. L.; Ferreira, T. G. 2003. Ocorrência de Thamnodynastes strigatus (Serpentes, Colubridae) no Escudo das Guianas, estados do Pará e Roraima, Brasil. Phyllomedusa, 2(2): 117-19.

Franco, F. L.; Cintra, L. A. C.; Lema, T. 2006. A new species of Calamodontophis Amaral, 1963 (Serpentes, Colubridae, Xenodontinae) from Souhtern Brazil. South Am. J. Herpetol., 1(3): 218-226.

Franco, F. L.; Ferreira, T. G.; Marques, O. A. V.; Sazima, I. 2003. A new species of hooddisplaying Thamnodynastes (Serpentes: Colubridae) from the Atlantic forest in southeast Brazil. Zootaxa, 334: 1-7.

Franco, F. L.; Salomão, E. L.; Borges-Martins, M.; Di-Bernardo, M.; Meneghel, M. D.; Carreira, S. 2001. New records of Calamodontophis paucidens (Serpentes, Colubridae, Xenodontinae) from Brazil and Uruguay. Cuad. Herp., 14: 155-159.

França, F. G. R.; Araújo, A. F. B. 2006. The conservation status of snakes in central Brazil. South Am. J. Herpetol., 1(1): 25-36.

Frazzetta, T. H. 1966. Studies on the morphology and function of the skull in the Boidae (Serpentes). J. Morph., 118: 217-296.

Fujita, M. K.; Leache, A. D. 2011. A coalescent perspective on delimiting and naming species: a reply to Bauer et al. Proc. R. Soc. B, 278: 493-495.

Fujita, M. K.; Leache, A. D.; Burbrink, F. T.; McGuire, J. A.; Moritz, C. 2012. Coalescentbased species delimitation in an integrative taxonomy. Trends Ecol. Evol., 27, 480488.

Gallardo, J. 1972. Observaciones biológicas sobre una falsa yarará, Tomodon ocellatus Duméril, Bribon et Duméril. Neotropica, 18: 57-63. 
Gallordo, F. B.; Stazzonelli, J. C.; Baldo, J. 2014. Ampliación del rango de distribución de Tomodon orestes Harvey y Muñoz, 2004 (Serpentes: Dipsadidae) para el território argentino. Cuad. Herpetol., 28(2):1-3.

Gans, C. 1964. A redescription of, and geographic variation in, Liophis miliaris Linné, the common water snake of southeastern South America. Am. Mus. Novit., 2178: 1-58.

García-Díez, T.; González-Fernández, J. E. 2013. The reptile type specimens preserved in the Museo Nacional de Ciencias Naturales (CSIC) of Madrid, Spain. Zootaxa, 3619 (1):4658.

Gauthier, J. A.; Kearney, M.; Maisano, J. A.; Rieppel, O.; Behlke, A. D. B. 2012. Assembling the Squamate Tree of Life: Perspectives from the Phenotype and the Fossil Record. Bull. Peabody Mus. Nat. Hist., 53(1): 3-308.

Gatesy, J.; O'Leary, M. A. 2001. Deciphering whale origins with molecules and fossils. Trends Ecol. Evol., 16: 562-570.

Ghizoni, Jr. I. R.; Kunz, T. S.; Cherem, J. J.; Bérnils, R. S. 2009. Registros notáveis de répteis de áreas abertas naturais do planalto e litoral do estado de Santa Catarina, sul do Brasil. Biotemas, 22(3): 129-141.

Girard, C. F. 1854. Abstract of a report to Lieut. James M. Gilliss, U.S.N., upon the Reptiles collected during the U.S.N. Astronomical Expedition to Chili. Proc. Acad. Nat. Sc. Philad., VII: 226.

Girard, C. F. 1855. Contributions to the fauna of Chile. Report to Lieut. James M. Gilliss, U. S. N., upon the fishes collected by the U. S. Naval Astronomical Expedition to the southern hemisphere during the years 1849-50-51-52. Washington. 1858, 2 vols., 42 pls.

Giraudo, A. R. 1996. Geographic distribution. Thamnodynastes chaquensis (Chaco Coastal House snake. Paraguay: Neembucu. Herp. Rev., 27(4):215.

Giraudo, A. R.; Scrocchi, G. J. 2002. Argentinian snakes: an annotated checklist. Smith. Herpetol. Info. Ser., 132:1-53.

Giraudo, A. R.; Vidoz, F.; Arzamendia, V.; Nenda, S. J. 2012. Distribution and natural history notes on Tachymenis chilensis chilensis (Schlegel, 1837) (Reptilia: Serpentes: Dipsadidae) in Argentina. Check List, 8(5): 919-923.

Goloboff, P. A.; Farris, J. S.; Nixon, K. C. 2008. TNT, a free program for phylogenetic analysis. Cladistics, 24: 774-786.

Gomes, J. F. 1915. Contribuição para o conhecimento dos ofídios do Brasil. Descrição de quatro espécies novas e um novo gênero de opistóglifos. An. Paul. Med. Cir., 4: 121- 
129.

Gomes, J. F. 1918. Contribuição para o conhecimento dos ofídios do Brasil III. Descrição de duas espécies novas. Mem. Inst. Butantan, 1: 57-83.

Gonzalez, R. C.; Prudente, A. L. C.; Franco, F. L. 2014. Morphological variation of Gomesophis brasiliensis and Ptychophis flavovirgatus (Serpentes, Dipsadidae, Xenodontinae). Salamandra, 50(2): 85-98.

Gorzula, S.; Ayarzagüena, J. 1995 (1996). Dos nuevas especies del género Thamnodynastes (Serpentes: Colubridae) de los tepuyes de la Guayana Venezolana. Publ. Asoc. Amigos Doñana, 6: 1-17.

Grazziotin, F. G.; Zaher, H.; Murphy, R. W.; Scrocchi, G.; Benavides, M. A.; Zhang, Y.; Bonatto, S. L. 2012. Molecular phylogeny of the New World Dipsadidae (Serpentes: Colubroidea): a reappraisal. Cladistics, 1: 1-23.

Greene, H. W.; Jaksic, F. M. 1993. The feeding behavior and natural history of two Chilean snakes, Philodryas chamissonis and Tachymenis chilensis (Colubridae). Rev. Chil. Hist. Nat., 65: 485- 493.

Groombridge, B. C. 1979. On the vomer in Acrochordidae (Reptilia: Serpentes), and its cladistic significance. J. Zool. Lond., 189: 559-567.

Guedes, T. B. 2010. Geographic Distribution. Thamnodynastes almae. Herp. Rev., 41 (2): 245.

Guedes, T. B.; Nogueira, C.; Marques, O. V. A. 2014. Diversity, natural history, and geographic distribution of snakes in the Caatinga, Northeastern Brazil. Zootaxa, 3863: $1-93$.

Guerreiro, A.; Baldoni, J. C.; Brigada, A. M. 2005. Herpetofauana de Sierra de Las Quijadas (San Luis, Argentina). Gayana, 69(1): 6-9.

Günther, A. 1858. Catalogue of Colubrine snakes of the British Museum. London, I XVI, 1-281.

Hamdan, B.; Lira-da-Silva, R. M. 2012. The snakes of Bahia State, northeastern Brazil: species richness, composition and biogeographical notes. Salamandra, 48: 31-50.

Hammer, Ø.; Harper, D. A. T.; Ryan, P. D. 2001. PAST: Paleontological Statistics Software Package for Education and Data Analysis. Palaeontologia Electronica, 4(1): 9. http://palaeo-electronica.org/2001_1/past/issue1_01.htm

Harvey, M. B.; Embert, D. 2008. Review of Bolivian Dipsas (Serpentes: Colubridae) with comments on other South American species. Herp. Monog., 22:54-105.

Harvey, M. B.; Muñoz, A. 2004. A new species of Tomodon (Serpentes: Colubridae) from 
high elevations in the Bolivian Andes. Herpetologica, 60(3): 364-372.

Hebert, P. D.; Penton, E. H.; Burns, J. M.; Janzen, D. H.; Hallwachs, W. 2004. Ten species in one: DNA barcoding reveals cryptic species in the Neotropical skipper butterfly Astraptes fulgerator. PNAS, 101(41): 14812-14817.

Heise, P. J.; Maxson, L. R.; Dowling, H. G.; Hedges, S. B. 1995. Higher level snake phylogeny inferred from mitochondrial DNA sequences of 12S rRNA and 16S rRNA genes. Mol. Biol. Evol., 12, 259-265.

Heled, J.; Drummond, A. J. 2010. Bayesian inference of species trees from multilocus data. Mol. Biol. Evol., 27(3): 570-80.

Hillis, D. M.; Wiens, J. J. 2000. Molecules versus morphology in systematics: Conflicts, artifacts, and misconceptions. Pp. 1-19. In: Phylogenetic analysis of morphological data. J. J. Wiens (ed.). Smithsonian Institution Press, Washington, DC.

Hoge, A. R. 1952 (1953). Notas erpetológicas. Revalidação de Thamnodynastes strigatus (Günther, 1858). Mem. Inst. Butantan, 24(2): 157-172.

Hoge, A. R. 1959 (1957/58). Note sur la position systematique de Opisthoplus degener Peters, 1882 et Leimadophis regina macrosoma Amaral 1935 (Serpentes). Mem. Inst. Butantan, 28: 67-72.

Hoge, A. R; Mertens, R. 1959. Eine neue Gattung opisthoglypher Nattern aus Brasilien. Senck. Biol., 40(5/6): 241-43.

Hoge, A. R.; Romano, S. A. 1969. Nota sobre Siphlophis e Ptychophis. Ciênc. Cult., 21: 454. Hoogmoed, M. S. 1982. Snakes of the Guianan region. Mem. Inst. Butantan, 16:219-254. Huelsenbeck, J. P.; Ronquist, F. 2001. MRBAYES: Bayesian inference of phylogenetic trees. Bioinformatics, 17: 754-5.

Jackson, K. 2003. The evolution of venom-delivery systems in snakes. Zool. J. Linn. Soc., 137: $227-354$.

Jan, G. 1863. Enumerazione Sistematica degli ofidi appartenenti al grupo Coronellidae. Arch. Zool. Anat. Fisiol., 2 (2): 215-330.

Jan, G.; Sordeli, F. 1866. Iconographie Générale des Ophidiens. Milano, livr. 18, pl. 16, livr.19, pl. 1.

Jenner, J. V. 1981. A Zoogeographic study and the taxonomy of the Xenodontine colubrid snakes. Tese (Doutorado) New York University.

Jenner, J. V.; Dowling, H. G. 1985. Taxonomy of American xenodontine snakes: the tribe Pseudoboini. Herpetologica, 41:161-172. 
Jorge, J. S.; Freire, E. M. X. 2011. Geographic Distribution. Thamnodynastes almae. Herp. Rev., 42: 396.

Joventino, I. J.; Ribeiro, S. C.; Melo, J. C. L. 2009. Geographic distribution: Thamnodynastes almae. Herp. Rev., 40: 238.

Katoh, K.; Misawa, K.; Kuma, K.; Miyata, T. 2002. MAFFT: a novel method for rapid multiple sequence alignment based on fast Fourier transform. Nucleic Acids Res., 30: 3059-3066.

Kearse, M.; Moir, R.; Wilson, A.; Stones-Havas, S.; Cheung, M.; Sturrock, S.; Buxton, S.; Cooper, A.; Markowitz, S.; Duran, C.; Thierer, T.; Ashton, B.; Mentjies, P.; Drummond, A. 2012. Geneious Basic: an integrated and extendable desktop software platform for the organization and analysis of sequence data. Bioinformatics, 28(12), 1647-1649.

Kelly, C. M. R.; Baker, N. P.; Villet, M. H. 2003. Phylogenetics of advanced snakes (Caenophidia) based on four mitochondrial genes. Syst. Biol., 52: 439-459.

Kitching, I. J.; Forey, P. L.; Humphries, C. J.; Williams, D. M. 1998. Cladistics. Oxford, Oxford University Press, 2nd ed. 228 pp.

Klackzko, J.; Montingelli, G. G.; Zaher, H. 2014. A combined morphological and molecular phylogeny of the genus Chironius Fitzinger, 1826 (Serpentes: Colubridae). Zool. J. Linn. Soc., 2014: 1-12.

Kochva, E. 1978. Oral glands of the reptilia. Pp. 43-161. In: Biology of the Reptilia, Vol. 8, Physiology B. C. Gans and K. A. Gans (eds.), Academic Press, London, U.K.,

Kochva, E.; Wollberg, M. 1970. The salivary glands of Aparallactinae (Colubridae) and the venom glands of Elaps (Elapidae) in relation to the taxonomic status of this genus. Zool. J. Linn. Soc., 49:217-224.

Koslowsky, J. 1896. Sobre algunos reptiles de Patagonia y otras regiones Argentinas. Rev. Mus. La Plata, 7: 448-457.

Kornacker, P. M. 1999. Checklist and key to the snakes of Venezuela. PaKo-Verlag, Rheinbach, Germany, 270 pp.

Kraus, F.; Brown, W. M. 1998. Phylogenetic relationships of colubrid snakes based on mitochondrial DNA sequences. Zool. J. Linn. Soc., 122: 455-487.

Lanfear, R.; Calcott, B.; Ho, S. Y. W.; Guindon, S. 2012. PartitionFinder: Combined selection of partitioning schemes and substitution models for phylogenetic analyses. Mol. Biol. Evol., 29: 1695-1701.

Langebartel, D. A. 1968. The hyoid and its associated muscles in snakes. Illinois Biol. 
Monogr., 38: 1-156.

Laporta-Ferreira, I. L.; Salomão, M. G.; Sawaya, P. 1986. Biologia de Sibynomorphus (Colubridae - Dipsadinae) - reprodução e hábitos alimentares. Rev. Bras. Biol., 46(4): 793-799.

Laporta-Ferreira, I. L.; Salomão, M. G.; Sawaya, P.; Puorto, G. 1988. Mecanismo de tomada de alimento por serpentes tropicais moluscófagas (Sibynomorphus neuwiedi e Sibynomorphus mikanii) adaptações morfofisiológicas do esqueleto cefálico. Bol. Fisiol. Anim. São Paulo, 12:81-88.

Lawson, R.; Slowinski, J. B.; Crother, B. I.; Burbrink, F. T. 2005. Phylogeny of the Colubroidea (Serpentes): new evidence from mitochondrial and nuclear genes. Mol. Phylog. Evol., 37, 581-601.

Lehr, E. 2002. Amphibien und Reptilien in Peru. Die Herpetofauna entlang des 10. Breitengrades von Peru: Arterfassung, Taxonomie, ökologische Bemerkungen und biogeographische Beziehungen. Dissertation, Natur- und Tier-Verlag, Naturwissenschaft, Münster, Germany, 208 pp.

Lema, T. 1967. Novo gênero e espécie de serpente opistoglifodonte do Brasil meridional ("Colubridae", "Colubrinae"). Iheringia (Zool), 35: 61-67.

Lema, T.; Deiques, C. H. 1992. Contribuição ao conhecimento da "cobra espada d'água", Ptychophis flavovirgatus Gomes, 1915 (Serpentes, Colubridae, Xenodontinae, Tachymenini). Com. Mus. Ciênc., PUC-RS (série zool), 5 (6): 55-83.

Lenk, P.; Kalyabina, S.; Wink, M.; Joger, U. 2001. Evolutionary relationships among the true vipers (Reptilia: Viperidae) inferred from mitochondrial DNA sequences. Mol. Phylog. Evol., 19: 94-104.

Leybold, F. 1873. Escursion a las Pampas Arjentinas. Hojas de mi diário. Imprenta "Nacional”, Calle de La Moneda Núm. 46. Santiago, Chile. 108 pp.

Lewis, P. O. 2001. A Likelihood Approach to Estimating Phylogeny from Discrete Morphological Character Data. Syst. Biol., 50(6): 913-925.

Lombard, E. R. 1986. Morphometrics of the ectopterygoid in advanced snakes (Colubroidea): a concordance of shape and phylogeny. Biol. J. Linn. Soc., 27: 133-164.

Lönnberg, E. 1896. Linnean type-specimens of birds, reptiles, batrachians, and fisches in the Zoological Museum of the R. University in Upsala. Bihang Till Koeniger Svenska Vetenskaps-Akademiens Handlingar, 22(4): 1-45.

Losos, J. B; Hillis, D. M.; Greene, H. W. 2012. Who Speaks with a Forked Tongue? State-ofthe-art molecular and morphological phylogenies for lizards differ fundamentally. 
Evolution, 338: 1428-1429.

Maddison, W. P.; Maddison, D. R. 2014. Mesquite: a modular system for evolutionary analysis. Version 3.0. http://mesquiteproject.org.

Manzanilla, J.; Sánchez, D. 2005 (2004). Una nueva especie de Thamnodynastes (Serpentes: Colubridae) del Macizo del Turimiquire, noreste de Venezuela. Mem. Fund. La Salle de Cienc. Nat., 161-162: 61-75.

Marques, R.; Tinôco, M. S.; Rödder, D.; Browne-Ribeiro, H. C. 2013. Distribution extension of Thamnodynastes pallidus and new records within the distribution of Erythrolamprus reginae, Imantodes cenchoa and Siphlophis compressus (Serpentes, Dipsadidae) for the north coast of Bahia, Brazil. Herpetol. Notes, 6: 529-532.

Marx, H.; Rabb, G. B. 1972. Phyletic analysis of fifty characters of advanced snakes. Fieldiana, Zool., 63: 1-321.

Masiero, R. L. 2006. Filogenia morfológica do gênero Xenodon Boie 1827 (Serpentes, Xenodontinae). Dissertação (Mestrado). Instituto de Biociências da Universidade de São Paulo. São Paulo, 149 pp.

McCulloch, R. D.; Lathrop, A.; Kok, P. J.; Ernst, R.; Kalamandeen, M. 2009. The genus Oxyrhopus (Serpentes: Dipsadidae: Xenodontinae) in Guyana: morphology, distributions and comments on taxonomy. Pap. Avul. Zool., 49(36): 487-495.

McDowell, S. B. 1986. The architecture of the corner of the mouth of colubroid snakes. J. Herpetol, 20(3), p. 353-407.

McDowell, S. B. 1987. Systematics. Pp. 3-50. In: Snakes: ecology and evolutionary biology. R. A. Seigel, J. T. Collins and S. S. Novak (eds.). Macmillan Publishing Company, New York.

Medina-Rangel, G. F. 2013. Cambio estacional en el uso de los recursos de la comunidad de reptiles en el complejo cenagoso de Zapatosa, Departamento del Cesar (Colombia). Caldasia, 35(1): 103-122.

Melgarejo, A. R. 2003. Serpentes peçonhentas do Brasil. Pp. 33-61. Em: Animais Peçonhentos no Brasil. Biologia, Clínica e Terapêutica dos Acidentes. J. L. C. Cardoso et al., (eds.). Sarvier, São Paulo.

Meyen, F. J. F. 1834. Reise urn die Erde in den Jahren, 1830, 31, und 32. Von Dr. F. J. F. Meyen. Berlin, 1834. (Voyage round the World in the years 1830, 31, and 32. By Dr. F. J. F. Meyen. Berlin, 1835). 2 vols. 4to.

Mikan, J. C. 1820. Delectus florae at faunae brasiliensis. - Viena, Typ. Antonii traus. 47p. 24pls. 
Miller, M. A.; Pfeiffer, W.; Schwartz, T. 2014. in Proceedings of the Gateway Computing Environments Workshop (GCE). (New Orleans, LA, 2014), pp. 1-8.

Miranda M. E.; Couturier, G. A. 1981. Una nueva subespécie de "Tachymenis peruviana" Wiegmann, 1835 (ophidia, Boigidae) para la Argentina. Mus. Arg. Cienc. Nat., Zool., 10:79-83.

Montingelli, G. G. 2004. Anatomia comparada das serpentes dos gêneros Ahaetulla, Oxybelis, Thelotornis, Uromacer e Xenoxybelis (Serpentes: Colubridae) e a evolução do focinho afilado nos colubrídeos. Dissertação (Mestrado). Instituto de Biociências da Universidade de São Paulo. São Paulo, 118 pp.

Motte, M.; Núñez, K.; Cacciali, P. Brusquetti, F.; Scott, N.; Aquino, A. L. 2009. Categorización del estado de conservación de los anfibios y reptiles de Paraguay. Cuad. Herpetol., 23 (1): 5-18.

Moura, M. R.; Motta, A. P.; Fernandes, V. D.; Feio, R. N. 2012. Herpetofauna from Serra do Brigadeiro, an Atlantic Forest remain in the state of Minas Gerais, Southeastern Brazil. $\begin{array}{lll}\text { Biota } & \text { Neotrop. 12(1): http:// }\end{array}$ www.biotaneotropica.org.br/v12n1/en/abstract?inventory+bn01012012012

Moura-Leite, J. C. 2001. Sistemática e Análise Filogenética das Serpentes da Tribo Xenodontini (Bonaparte, 1845) (Colubridae, Xenodontinae). Tese (Doutorado). Setor de Ciências Biológicas, Universidade Federal do Paraná. Curitiba, 158 pp.

Mulcahy, D.; Beckstead, T. H.; Sites, J. 2011. Molecular systematics of the Leptodeirini (Colubroidea, Dipsadidae) revisited: species tree analyses and multi-locus data. Copeia, 3: 407-417.

Myers, C. W.; Donnelly, M. A. 1996. A new herpetofauna from Cerro Yaví, Venezuela: First results of the Robert G. Goelet American Museum-Terramar expedition to the northwestern Tepuis. Am. Mus. Novit., 3172: 1-56.

Myers, C. W.; Hoogmoed, M. S. 1974. Zoogeographic and taxonomic status of the South American snake Tachymenis surinamensis (Colubridae). Zoölog. Med., Leiden, 48 (17): 187-194.

Myers, C. W.; Mcdowell, S. B. 2014. New Taxa And Cryptic Species Of Neotropical Snakes (Xenodontinae), With Commentary On Hemipenes As Generic And Specific Characters. Bull. Am. Mus. Nat. Hist., 385, 112 pp.

Nixon, K. C.; Wheeler, Q. D. 1990. An amplification of the phylogenetic species concept. Cladistics, 6: 211-223.

Nóbrega, R. P.; Montingelli, G. G.; Trevine, V.; Franco, F. L.; Vieira, G. H. C.; Costa, G. C.; 
Mesquita, D. O. 2016. Morphological variation within Thamnodynastes pallidus (Linnaeus, 1758) (Serpentes: Dipsadidae: Xenodontinae: Tachymenini). Herp. J., 26: 165-174.

Noonan, B. P.; Chippindale, P. T. 2006. Vicariant origin of malagasy reptiles supports late cretaceous antarctic land bridge. Am. Nat., 168: 730-741.

Nori, J.; Gómez, J. M. D.; Leynaud, J. C. 2011. Biogeographic regions of Central Argentina based on snake distribution: evaluating two different methodological approaches. J. Nat. Hist., 45:17-18: 1005-1020.

Nunes, P. M. S. 2006. Filogenia da tribo Hydropsini baseada em caracteres morfológicos (Serpentes: Xenodontinae). Dissertação (Mestrado). Departamento de Biociências da Universidade de São Paulo. São Paulo, 130 pp.

Oguiura, N.; Ferrarezzi, H.; Batistic, R. F. 2010. Cytogenetics and molecular data in snakes: a phylogenetic approach. Cytogenet. Genome Res., 127:128-142.

Oliveira, J. L; Borges, M.; Marques, O. A. V. 2003. Gomesophis brasiliensis (NCN): Reproduction and diet. Herp. Rev., 34 (3): 251-252.

Oliveira, L. 2013. Especializações glandulares, musculares e dentárias dos dipsadíneos "goo-eaters" (Serpentes: Dipsadinae) associadas à ingestão de suas presas. Tese (Doutorado), Universidade Estadual Paulista, Instituto de Biociências de Rio Claro. Rio Claro $212 \mathrm{pp}$.

Oliveira, L.; Jared, C.; Prudente, A. L. C.; Zaher, H.; Antoniazzi, M. M. 2008. Oral glands in dipsadinae "goo-eater" snakes: Morphology and histochemistry of the infralabial glands in Atractus reticulatus, Dipsas indica, and Sibynomorphus mikanii. Toxicon, n. 51: 898-913.

Ortiz, J. C. 1973. Étude sur le statut taxonomique de Tachymenis peruviana Wiegmann et Tachymenis chilensis (Schlegel) (Serpentes: Colubridae). Bull. Mus. Nat. Hist. Natur., 146:1021-1039.

Padial, J. M.; Miralles, A.; De la Riva, I.; Vences, M. 2010. The integrative future of taxonomy. Front. Zool., 7: 16.

Pagini, E.; Lema T. 1987. Reencontro de Calamodontophis paucidens (Amaral, 1935) e contribuição ao conhecimento do gênero e espécie (Serpentes, Colubridae, Tachymeninae). Com. Mus. Ciênc. PUC-RS, Porto Alegre, 47:195-208.

Parker, H. W. 1935. The frogs, lizards and snakes of British Guiana. Proc. Zool. Soc., 1935: 505-530.

Passos, P.; Fernandes, R.; Bérnils, R. S.; Moura-Leite, J. C. 2010. Taxonomic revision of the 
Brazilian Atlantic Forest Atractus (Reptilia: Serpentes: Dipsadidae). Zootaxa, 2364: 163.

Pefaur, J. E.; Davila, J.; Lopwz, E.; Nuñez, A. 1978. Distribucion y clasificacion de los reptiles del departamento de Arequipa. Bull. Inst. Fr., 7(1-2): 129-139.

Peracca, M. G. 1897. Sopra un nuovo genere di colubride opistóglifo dela Repubblica Argentina. Boll. Mus. Zool. Anat. Comp. Torino, 12(278): 1-2.

Pérez-Santos, C.; Moreno, A. G. 1989. Una nueva especie de Thamnodynastes (Serpentes: Colubridae) en el norte de Colombia. Boll. Mus.Reg. Scien. Nat., Torino, 7(1): 1-9.

Pesantes, O. S. 1994. A method for preparing the hemipenis of preserved snakes. J. Herpetol., 28: 93-95.

Peters, W. 1882. Über Opisthoplus degener, eine neue Gattung und Art der Schlangen mit ganz eigenthümlicher Bezahnung. Sitzungsbericht Akademien Wissenchaften zu Berlin, 52: 1147-1150.

Peters, J. A. 1960. The snakes of Ecuador. Check list and key. Bull. Mus. Comp. Zool., 112(9): 491-541.

Peters, J. A. 1964. Dictionary of Herpetology. Hafner, New York. vii + 392 pp.

Peters, J. A.; Orejas-Miranda, B. 1970. Catalogue of Neotropical Squamata. Part 1. Snakes. Bull. Unit. States Nat. Mus., 297: 1-347.

Philippi, R. A. 1899. Sobre las serpientes de Chile. Ann. Univ. Chile, 104: 715-725.

Pinna, M. G. G. 1991. Concepts and tests of homology in the cladistic paradigm. Cladistics, 7:367-394.

Pinou, T.; Vicario, S.; Marschner, M.; Caccone, A. 2004. Relict snakes of North America and their relationships within caenophidia, using likelihood-based Bayesian methods on mitochondrial sequences. Mol. Phylog. Evol., 32: 563-574.

Pook, C. E.; Wüster, W.; Thorpe, R. S. 2000. Historical biogeography of the Western Rattlesnake (Serpentes: Viperidae: Crotalus viridis), inferred from Mitochondrial DNA sequence information. Mol. Phylog. Evol., 15: 269-282.

Porto, M.; Caramaschi, U. 1988. Notes on the Taxonomic status, Biology, and distribution of Ptychophis flavovirgatus Gomes, 1915 (Ophidia, Colubridae). Rev. Bras. Biol., 60 (4): 471-475.

Prado, A. 1942. Serpentes do gênero Dryophylax, com a descrição de uma nova espécie. Ciência, México, 3(7): 204-205.

Prado, A. 1943. Notas ofiológicas 15. Serpentes do gênero Dryophylax, com a redescrição de uma nova espécie. Mem. Inst. Butantan, 17:1-4. 
Prado, A. 1947. Notas ofiológicas. Descriçao do alótipo de Dryophylax rutilus Prado, 1942. Mem. Inst. Butantan, 20:189-192.

Prudente, A. L. C. 1993. Revisão do gênero Gomesophis Hoge et Mertens (1959), com algumas considerações sobre a tribo Tachymenini (Serpentes, Colubridae, Xenodontinae). Dissertação (Mestrado). Faculdade de Biociências, PUC. Porto Alegre, $142 \mathrm{pp}$.

Prudente, A. L. C.; Brandão, R. 1998. A. Geographic Distribution. Gomesophis brasiliensis. Herp. Rev., 29(2): 112.

Pyron, R. A.; Burbrink, F. T.; Colli, G. R.; Montes de Oca, A. N.; Vitt, L. J.; Kuczynski, C. A.; Wiens, J. J. 2011. The phylogeny of advanced snakes (Colubroidea), with discovery of a new subfamily and comparison of support methods for likelihood trees. Mol. Phylog. Evol., 58: 329-342.

Pyron, R. A.; Burbrink, F. T.; Wiens, J. J. 2013. A phylogeny and revised classification of Squamata, including 4161 species of lizards and snakes. BMC Evol. Biol., 13: 93.

Pyron, R. A.; Hendry, C. R.; Chou, V. M.; Lemmon, E. M.; Lemmon, A. R.; Burbrink, F. T. 2014. Effectiveness of phylogenomic data and coalescent species-tree methods for resolving difficult nodes in the phylogeny of advanced snakes (Serpentes: Caenophidia). Mol. Phylog. Evol., 81: 221-231.

R Core Team 2013. R: A language and environment for statistical computing. R Foundation for Statistical Computing. Vienna, Austria. URL http://www.R-project.org/.

Rambaut, A.; Drummond, A. 2007. Tracer ver. 1.4. Program available at http://beast. bio. ed. ac. $\mathrm{uk} /$ Tracer.

Ravaoarimanana, I. B.; Tiedmann, R.; Montagnon, D.; Rumpler, Y. 2004. Molecular and cytogenetic evidence for cryptic speciation within a rare endemic Malagasy lemur, the Northern Sportive Lemur (Lepilemur septentrionalis). Mol. Phyl. Evol., 31: 440-448.

Rivas, G. A.; Molina, C. R.; Ugueto, G. N.; Barros, T. R.; Barrio-Amorós, C. L.; Kok, P. J. 2012. Reptiles of Venezuela: an updated and commented checklist. Zootaxa, 3211: 164.

Reeder, T. W.; Townsend, T. M.; Mulcahy, D. G.; Noonan, B. P.; Wood, P. L. Jr.; Sites, J. W. Jr.; Wiens, J. J. 2015. Integrated Analyses Resolve Conflicts over Squamate Reptile Phylogeny and Reveal Unexpected Placements for Fossil Taxa. PLoS ONE, 10(3): 122. e0118199. doi:10.1371/journal.pone.0118199.

Roberto, I. J.; Ribeiro, S. C.; Melo, J. C. L. 2009. Geographic Distribution. Thamnodynastes almae. Herp. Rev., 40: 239. 
Romer, A. S. 1956. Osteology of the Reptiles. University of Chicago Press, Chicago. 772 pp.

Roze, J. A. 1958. Los reptiles de Chimanta Tepui (Estado Bolivar, Venezuela) colectados por la expedición botánica del Chicago Natural History Museum. Acta Biol. Venez., 2(25): 299-314.

Roze, J. A. 1966. La taxonomía y zoogeografía de los ofídios en Venezuela. Universidad Central de Venezuela. Ediciones de la Biblioteca. 133 pp.

Ruane, S.; Bryson Jr. R. W.; Pyron R. A.; Burbrink, F. T. 2014. Coalescent Species Delimitation in Milksnakes (Genus Lampropeltis) and Impacts on Phylogenetic Comparative Analyses. Syst. Biol., 63(2): 231-250.

Santos, Jr. A. 2009. Revisão Taxonômica do Grupo de Taeniophallus occipitalis e o Relacionamento Filogenético da Tribo Echinantherini (Serpentes, Dipsadidae, Xenodontinae). Tese (Doutorado). Departamento de Zoologia, PUC, Rio Grande do Sul. Porto Alegre, 241 pp.

Savitzky, A. H. 1979. The origin of the New World proteroglyphous snakes and its bearing on the study of venom delivery systems in snakes. Tese (Doutorado). University of Kansas, Lawrence.

Sazima, I. 1989. Feeding behavior of the snail-eating snake, Dipsas indica. J. Herpetol., 23: 464-468.

Scartozzoni, R. S; Marques, O. A. V. 2004. Sexual dimorphism, reproductive cycle, and fecundity of the water snake Ptychophis flavovirgatus (Serpentes, Colubridae). Phyllomedusa, 3(1): 69-71.

Schlegel, H. 1837. Essai sur la Physionomie des Serpents, II. La Haye, 606 pp.

Schmidt, K. P.; Walker, W. F. Jr. 1943a. Peruvian snakes from the University of Arequipa. Zool. Ser. Field Mus. Nat. History, 24 (26): 279-296.

Schmidt, K. P.; Walker, W. F. Jr. 1943b. Snakes of the Peruvian coastal region. Zool. Ser. Field Mus. Nat. History, 24 (27): 297-324.

Schwartz, A.; Henderson, R. W. 1991. Amphibians and Reptiles of the West Indies. Descriptions, Distributions, and Natural History. University of Florida Press, 727 p.

Schuh, R. T.; Brower, A. V. Z. 2009. Biological Systematics. Principles and applications. 2nd ed. Cornell University Press. 311 pp.

Scrocchi, G. J. 1997. Acerca de la localidade tipo de Bothrops ammodytoides Leybold (Serpentes, Viperidae) y Pseudotomodon trigonatus (Leybold) (Serpentes: Colubridae). Cuad. Herp., 11(1-2): 69-70. 
Scrocchi, G. J.; Abdala, C. S.; Nori, J.; Zaher, H. 2010. Reptiles de La Provincia de Río Negro, Argentina. 1ed. Viedma, Fondo Editorial Rionegrino, 252 pp.

Scrocchi, G. J.; Moreta, J. C.; Kretzschmar, S. 2006. Serpientes del Noroeste Argentino. Fundación Miguel Lillo. 174p.

Sereno, P. C. 2007. Logical basis for morphological characters in phylogenetics. Cladistics, 23: $565-587$.

Silva, E. P. 2010. Revisão taxonômica de um grupo de serpentes da Mata Atlântica: Tropidodryas Fitzinger, 1843 (Serpentes, Dipsadidae). Dissertação (Mestrado). Faculdade de Biociências, PUC. Porto Alegre, 90 pp.

Silva, Jr. N. J.; Cintra, C. E. D.; Silva, H. L. R.; Costa, M. C.; Souza, C. A.; Pachêco Jr. A. A.; Gonçalves, F. A. 2009. Herpetofauna, Ponte de Pedra Hydroelectric Power Plant, states of Mato Grosso and Mato Grosso do Sul, Brazil. Check List, 5(3): 518-525.

Silveira, A. L. 2006. Geographic Distribution. Thamnodynastes longicaudus. Herp. Rev., 37 (3): 243.

Silveira, A. L.; Cotta, G. A. 2006. Geographic Distribution. Thamnodynastes sertanejo. Herp. Rev., 37: 364 .

Shine, R. 1994. Sexual dimorphism in snakes revisited. Copeia, 2:326-346

Slowinski, J. B.; Lawson, R. 2002. Snake Phylogeny: evidence from nuclear and mitochondrial genes. Mol. Phylog. Evol., 24: 194-202.

Song, J.; Parenti, L. R. 1995. Clearing and staining whole fish specimens for simultaneous demonstration of bone, cartilage, and nerves. Copeia, 1995: 114-118.

Stamatakis, A. 2014. RAxML Version 8: A tool for Phylogenetic Analysis and Post-Analysis of Large Phylogenies. Bioinformatics, 1-2.

Stamatakis, A.; Hoover, P.; Rougemont, J. 2008. A rapid bootstrap algorithm for the raxml web servers. Syst. Biol., 57(5), 758-771.

Taub, A. M. 1966. Ophidian cephalic glands. J. Morphol., 118:529-542.

Taub, A. M. 1967. Systematic implications from the labial glands of the Colubridae. Herpetologica, 23: 145-148.

Torstrom, S. M.; Pangle; K. L.; Swanson, B. J. 2014. Shedding subspecies: The influence of genetics on reptile subspecies taxonomy. Mol. Phylog. Evol., 76:134-143.

Tschudi, J. J. Von 1845. Untersuchungen iiber die Fauna Peruana. Herpetologie. St. Gallen, Scheitlin und Zollikofer, pp. 1-80, pis. 1-12.

Tucker, D. B; Colli, G. R.; Giugliano, L. G.; Hedges, S. B.; Hendry, C. R.; Lemmon, E. M.; Lemmon, A. R.; Sites, Jr. J. W.; Pyron, R. A. 2016. Methodological congruence in 
phylogenomic analyses with morphological support for teiid lizards (Sauria: Teiidae).

Mol. Phylog. Evol., 103: 75-84

Underwood, G. 1967. A contribution to the classification of snakes. Trustees of the British Museum (Natural History), Londres. 117 p.

Underwood, G. 2002. On the rictal structures of some snakes. Herpetologica, 58:1-17.

Underwood, G. Kochva, E. 1993. On the affinities of the burrowing asps Atractaspis (Serpentes: Atractaspididae). Zool. J. Linn. Soc., 107:3:64.

Uzzel, T. 1973. A revision of lizards of the genus Prionodactylus, with a new genus for $P$. leucostictus and notes on the genus Euspondylus (Sauria, Teiidae). Postilla, 159:1-67. Vaidya, G.; Lohman, D. J.; Meier, R. 2011. SequenceMatrix: Concatenation software for the fast assembly of multi-gene datasets with character set and codon information. Cladistics, 27: 171-180.

Valenzuela-Dellarossa, G.; Núñez, H.; Heibl, C.; Ortiz, J. C. 2010. Reptilia, Serpentes, Colubridae, Tachymenis Wiegmann, 1836: Latitudinal and altitudinal distribution extension in Chile. Check List, 6(1): 5-6.

Vanzolini, P. E. 1947. Sobre um gênero e espécie de colubrídeo opistóglifo. Pap. Avul. Zool., 8(14): 181-187.

Vanzolini, P. E. 1948. Notas sobre os ofídios e lagartos da Cachoeira de Emas, no municipio de Pirassununga, Estado de São Paulo. Rev. Bras. Biol., Rio de Janeiro 8(3): 377-400.

Vanzolini, P. E. 1986. Addenda and corrigienda to the Catalogue of the Neotropical Squamata. Smithson. Herpetol. Info. Service, 70: 1-26.

Vanzolini, P. E.; Costa, A. M. M. R.; Vitt, L. J. 1980. Répteis das Caatingas. Academia Brasileira de Ciências, Rio de Janeiro, 161 p.

Vega, L. E.; Bellagamba, P. J. 1994. Reptiles de la Reserva de usos múltiples caleta de Los Loros, Río Negro, Argentina. Cuad. Herpetol., 8(1): 141-145.

Vellard, J. 1955. Propriétés venimeuses de Tachymenis peruviana Wiegmann. Folia Biol. Andina, 1: 1-14.

Vidal, N.; Delmas, A. S.; David, P.; Cruaud, C.; Couloux, A.; Hedges, S. B. 2007. The phylogeny and classification of caenophidian snakes inferred from seven nuclear protein-coding genes. C. R. Biologies, 330: 182-187.

Vidal, N.; Dewynter, M.; Gower, D. J. 2010. Dissecting the major American snake radiation: A molecular phylogeny of the Dipsadidae Bonaparte (Serpentes, Caenophidia). C. R. Biologies, 333: 48-55. 
Vidal, N.; Kindl, S. G.; Wong, A.; Blair Hedges, S. 2000. Phylogenetic relationships of xenodontine snakes inferred from $12 \mathrm{~S}$ and $16 \mathrm{~S}$ ribosomal RNA sequences. Mol. Phylog. Evol., 14: 389-402.

Vidal, N.; Hedges, S. B. 2002. Higher-level relationships of caenophidian snakes inferred from four nuclear and mitochondrial genes. C. R. Biologies, 325: 987-995.

Wagler, J. 1824. Serpetum brasiliensium species novae. Monachii: Frac. Seraph. Hübschmann. Vii +75 pp.

Wagler, J. 1830. Natürliches System der Amphibien, mit vorangehender Classification der Säugthiere und Vögel. München, J.G. CotT. vi + 354p., 9 pl.

Wallach, V; Williams, K. L.; Boundy, J. 2014. Snakes of the world: A catalogue of living and extinct species. Taylor \& Francis Group, 1227 p.

Walker, W. F. 1945. A study of the snake Tachymenis peruviana Wiegmann and its allies. Bull. Mus. Comp. Zool. 96: 1-56.

Werner, F. 1898. Die Reptilien und Batrachier der Sämmling Plate. Zoologischer Jarbuk Supp. 4: 244-278, pl.13-14.

Werner, F. 1901. Reptilien und Batrachier aus Peru und Bolivien. Abh. Ber.K. Zool. Anthr. Ethn. Mus. Dresden, 9:9.

Werner, F. 1904. Hamburger Magalhensische Sammelreise. Reptilien und Batrachier: 1-21, $1 \mathrm{pl}$.

Wiegmann, A. F. A. 1835. Beitrage zur Zoologie, Gesammelt suf einer Reise um die Erde von F. J. F. Meyen. Abhandl. 7, Amphibien. N. Acta. Ac. Leop. Carol., 17: 183-268.

Wiens, J. J. 2004. The Role of Morphological Data in Phylogeny Reconstruction. Syst. Biol., 53(4): 653-661.

Wiens, J. J. 2009. Paleontology, phylogenomics, and combined-data phylogenetics: can molecular data improve phylogeny estimation for fossil taxa?. Syst. Biol., 58:87-99.

Wiens, J. J.; Kuczynski, C. A.; Townsend, T.; Reeder, T. W.; Mulcahy, D. G.; Sites Jr. J. W. 2010. Combining Phylogenomics and Fossils in Higher-Level Squamate Reptile Phylogeny: Molecular Data Change the Placement of Fossil Taxa. Syst. Biol., 59(6): $674-688$.

Wilcox, T. P.; Zwickl, D. J.; Heath, T. A.; Hillis, D. M. 2003. Phylogenetic relationships of the Dwarf Boas and a comparison of Bayesian and bootstrap measures of phylogenetic support. Mol. Phylog. Evol., 25: 361-371.

Yuki, R. N.; Santos, R. M. 1996. Snakes from Marajó and Mexiana islands, Pará state, Brazil. Bol. Mus. Par. Emilio Goeldi, Zool., 12:41-53. 
Zaher, H. 1994a. Comments on the evolution of the jaw adductor musculature of snakes. Zool. J. Linn. Soc., 111: 339-384.

Zaher, H. 1994b. Phylogénie des Pseudoboini et évolution des Xenodontinae sudaméricains (Serpentes: Colubridae). Tese (Doutorado). Muséum National d'Histoire Naturelle de Paris.

Zaher, H. 1996. A new genus and species of Pseudoboine snake, with a revision of the genus Clelia (Serpentes, Xenodontinae). Mus. Reg. Sci. Nat. Boll. (Turin), 14: 289-337.

Zaher, H. 1997. Description of the cephalic muscles and gland morphology of Clelia plumbea and three presumably related species (Serpentes, Xenodontinae). Pap. Avul. Zool., 40(2): 17-63.

Zaher, H. 1999. Hemipenial morphology of the South American xenodontine snakes, with a proposal for a monophyletic Xenodontinae and a reappraisal of colubroid hemimpenes. Bull. Am. Mus. Nat. Hist., 240: 1-168.

Zaher, H.; Grazziotin, F. G.; Cadle, J. E.; Murphy, R. W.; Moura-Leite, J. C.; Bonatto, S. L. 2009a. Molecular phylogeny of advanced snakes (Serpentes, Caenophidia) with an emphasis on South America xenodontines: a revised classification and descriptions of new taxa. Pap. Avul. Zool., 49:115-153.

Zaher, H.; Barbo, F. E.; Martínez, P. S.; Nogueira, C.; Rodrigues, M. T.; Sawaya R. J. 2009b. Reptiles from São Paulo State: current knowledge and perspectives. Biota Neotrop. 11(1a):

http://www.biotaneotropica. org.br/v11n1a/en/abstract?inventory+bn0051101a2011.

Zaher, H.; Prudente, A. L. C. 2003. Hemipenes of Siphlophis (Serpentes: Xenodontinae) and techniques of hemipenial preparation in snakes: a response to Dowling. Herp. Rev., 34 (4): 295-302.

Zar, J. H. 2010. Biostatistical Analysis. 5th ed. Prentice Hall, 944 p. 